\title{
Global gene expression analysis of apple fruit development from the floral bud to ripe fruit
} Bart J Janssen*1, Kate Thodey ${ }^{2}$, Robert J Schaffer ${ }^{1}$, Rob Alba ${ }^{3,8}$, Lena Balakrishnan ${ }^{4}$, Rebecca Bishop ${ }^{5}$, Judith H Bowen ${ }^{1}$, Ross N Crowhurst ${ }^{1}$, Andrew P Gleave ${ }^{1}$, Susan Ledger ${ }^{1}$, Steve McArtney ${ }^{6}$, Franz B Pichler ${ }^{7}$, Kimberley C Snowden ${ }^{1}$ and Shayna Ward ${ }^{1}$

\begin{abstract}
Address: 'The Horticulture and Food Research Institute of New Zealand Ltd., Mt Albert, Private Bag 92169, Auckland Mail Centre, Auckland 1142 New Zealand, 2John Innes Centre, Colney Lane, Norwich NR4 7UH, UK, ${ }^{3}$ Boyce Thompson Institute for Plant Research, Tower Road, Cornell University Campus, Ithaca, NY 14853, USA, ${ }^{2} 22$ Ramphal Terrace, Khandallah, Wellington, New Zealand, 54 La Trobe Track, RD2 New Lynn, Karekare, Auckland, New Zealand, ${ }^{6}$ Department of Horticultural Science, North Carolina State University, Mountain Horticultural Crops Research and Extension Centre, 455 Research Drive, Fletcher, NC 28732-9244, USA, ${ }^{7}$ Microbial Ecology \& Genomics Lab, School of Biological Sciences, University of Auckland, Auckland, New Zealand and ${ }^{8}$ Monsanto Company - O3D, Product Safety Center, 800 North Lindbergh Blvd., St. Louis, MO 63167, USA

Email: Bart J Janssen* - bjanssen@hortresearch.co.nz; Kate Thodey - Kate.Thodey@bbsrc.ac.uk; Robert J Schaffer - RSchaffer@hortresearch.co.nz; Rob Alba - rma28@cornell.edu; Lena Balakrishnan - lena.b@xtra.co.nz; Rebecca Bishop - becklesbishop@hotmail.com; Judith H Bowen - jbowen@ hortresearch.co.nz; Ross N Crowhurst - rcrowhurst@hortresearch.co.nz; Andrew P Gleave - AGleave@hortresearch.co.nz; Susan Ledger - SLedger@hortresearch.co.nz; Steve McArtney - Steve_McArtney@ncsu.edu; Franz B Pichler - f.pichler@auckland.ac.nz; Kimberley C Snowden - KSnowden@hortresearch.co.nz; Shayna Ward - sward@ hortresearch.co.nz

* Corresponding author
\end{abstract}

Published: 17 February 2008

BMC Plant Biology 2008, 8:16 doi:10.1 I86/147|-2229-8-16
Received: 13 September 2007

Accepted: 17 February 2008

This article is available from: http://www.biomedcentral.com/I47I-2229/8/16

(C) 2008 Janssen et al; licensee BioMed Central Ltd.

This is an Open Access article distributed under the terms of the Creative Commons Attribution License (http://creativecommons.org/licenses/by/2.0), which permits unrestricted use, distribution, and reproduction in any medium, provided the original work is properly cited.

\begin{abstract}
Background: Apple fruit develop over a period of 150 days from anthesis to fully ripe. An array representing approximately 13000 genes (15726 oligonucleotides of 45-55 bases) designed from apple ESTs has been used to study gene expression over eight time points during fruit development. This analysis of gene expression lays the groundwork for a molecular understanding of fruit growth and development in apple.
\end{abstract}

Results: Using ANOVA analysis of the microarray data, 1955 genes showed significant changes in expression over this time course. Expression of genes is coordinated with four major patterns of expression observed: high in floral buds; high during cell division; high when starch levels and cell expansion rates peak; and high during ripening. Functional analysis associated cell cycle genes with early fruit development and three core cell cycle genes are significantly upregulated in the early stages of fruit development. Starch metabolic genes were associated with changes in starch levels during fruit development. Comparison with microarrays of ethylene-treated apple fruit identified a group of ethylene induced genes also induced in normal fruit ripening. Comparison with fruit development microarrays in tomato has been used to identify 16 genes for which expression patterns are similar in apple and tomato and these genes may play fundamental roles in fruit development. The early phase of cell division and tissue specification that occurs in the first 35 days after pollination has been associated with up-regulation of a cluster of genes that includes core cell cycle genes.

Conclusion: Gene expression in apple fruit is coordinated with specific developmental stages. The array results are reproducible and comparisons with experiments in other species has been used to identify genes that may play a fundamental role in fruit development. 


\section{Background}

Fruit-bearing crop species are an important component of the human diet providing nutrition, dietary diversity and pleasure. Fruit are typically considered an enlarged organ that surrounds the developing seeds of a plant, or the ripened ovary of a flower together with any associated accessory parts [1]. The development and final form of the fruiting body is widely varied, ranging from minimally expanded simple dehiscent (non-fleshy) fruit of the model plant Arabidopsis, through expanded ovaries of tomato, to complex fruiting organs with several different expanded tissues, such as found in the pome fruit [1]. Common to all fruit is the developmental process that results in expansion of tissue near the seed in a coordinated manner with seed development (usually, but not always, enclosing the seed). At early stages during development (both before and after successful fertilization, and sometimes in the absence of fertilization) the fruit tissue undergoes several rounds of cell division, followed (usually) by cell expansion during which the fruit stores metabolites and energy, in the form of starch or sugars (e.g. tomato development [2-4]). Subsequently, usually after the seeds mature, the fruit undergoes a series of biochemical changes that convert starches into more available and attractive compounds, such as sugars, as well as producing volatile secondary metabolites that are thought to function as attractants for animals or insects which disperse the seed.

Morphological and physiological studies of fruit have led to considerable understanding of the physical and biochemical events that occur as fruit mature and ripen $[1,3,5]$, however it is only relatively recently that genomic approaches have been used to investigate fruit development [4,6-9]. As a result of excellent genetic resources and the application of molecular and genomic approaches, tomato has become the best studied indehiscent fruit. Domestication of tomatoes has resulted in the increase of fruit size from a few grams to varieties 1000-fold larger [10]. The physiological events leading to the expansion of the ovary wall of the tomato flower and in particular the events that occur around tomato ripening have been well described (for reviews see Gillaspy et al. [2]; Giovanonni [3]). More recently, molecular approaches have been used to study global gene expression in tomato [11-13] allowing identification of large numbers of genes potentially involved in fruit development and ripening.

In other fruit crops, microarrays have been used to examine gene expression during the development and in particular the ripening of fruits such as strawberry [6], peach [14], pear [15], and grape [8,9]. These studies have identified genes involved in fruit flavour and genes associated with distinct stages of fruit development.
Apples (Malus $\times$ domestica Borkh. also known as M. pumila) are members of the Rosaceae family, sub family pomoideae, which includes crop species such as pear, rose and quince. Members of the pomoideae have a fruit that consists of two distinct parts: an expanded ovary corresponding to the "core" which is homologous to the tomato fruit; and the cortex or edible portion of the fruit which is derived from the fused base of stamens, petals and sepals $[1,16]$, which expands to surround the ovary. Fruit develop over a period of 150 days from pollination to full tree ripeness with a simple sigmoidal growth curve $[17,18]$. Physiological studies of apple fruit development have focused on measures of ripeness such as colour changes and breakdown of starch to form the palatable sugars. From such studies, it has been shown that floral buds contain a small amount of starch that is metabolized quickly after pollination. Starch levels then build up in fruit coordinate with cell expansion. At about 100 days after pollination starch levels begin to decline again and fruit sugars increase, until the fruit are fully ripe [19]. Like tomato, apple undergoes an ethylene-dependent ripening stage $[20,21]$ and transgenic apples with reduced ethylene production fail to produce skin colour changes and appear to lack production of volatile compounds typically associated with apples [22].

Apple is functionally a diploid with $2 \mathrm{n}=34$ and a genome of moderate size $(1 \mathrm{C}=2.25 \mathrm{pg}$ [23] which corresponds to approximately $\left.1.5 \times 10^{9} \mathrm{bp}\right)$ making genomic approaches to the study of its biology reasonable. Recently an EST sequencing approach has been used to identify apple genes [24]; unigenes derived from this sequencing project were used to design the oligonucleotides used in this work. Two groups have published apple microarray analyses [22,25]. Lee et al. [25] used a 3484 feature cDNA array to identify 192 apple cDNAs for which expression changes during early fruit development. Using the same 13000 gene (15726 feature) apple oligonucleotide array described in this paper, Schaffer et al. [22] identified 944 genes in fruit that respond to ethylene treatment and associated changes in gene expression with changes in fruit volatiles.

In the work described in this paper, microarrays have been used to study the developmental processes occurring during fruit formation from pollination to full tree ripeness. In pome fruit both core (ovary) and cortex (hypanthium) tissues expand. Understanding the regulation of the events required to produce a complex apple fruit, including the division and expansion of cells from different floral structures is the ultimate aim of this work. Using microarrays we show that large groups of genes are coordinately expressed at specific stages of fruit development. We have identified cell division genes for which expression coincides with the period of cell division in 
apple fruit and have identified starch metabolic enzymes likely to be involved as fruit store and then metabolize starch. Using a comparative approach we have identified a number of genes for which expression patterns are similar in both apple and tomato fruit development and may be involved in similar fundamental processes in fruit development.

\section{Results \\ Microarray analysis of apple fruit development}

When apple trees (Malus domestica 'Royal Gala') were at full bloom (greater than $50 \%$ of buds open) individual fully open flowers were tagged and trees separated into two biological replicates (Rep1 and Rep2). Based on physiological and morphological studies of apple fruit development $[17,19]$ eight time points were selected for sampling (Figure 1). The first sample 0 Days After Anthesis (DAA) was taken at the same time that fully open flowers were tagged. The 14 and 25 DAA sampling time points coincide with the period of cell division that occurs after pollination. At 35 DAA cell division has ceased, the rate of cell expansion increases and starch accumulation begins. 60 DAA coincides with the greatest rate of cell expansion and starch accumulation. By 87 DAA the rate of cell expansion has declined but cell expansion continues at a reduced rate until full ripeness, starch levels peak shortly after this timepoint. In the year in which the samples were taken harvest ripeness was at 132 DAA, at this stage starch levels are rapidly declining and fruit sugars increasing, skin colour is still changing and while some flavour compounds are present full "apple flavour" has not yet developed. By 146 DAA fruit were "tree ripe" at this stage fruit have strong colour and have fully developed flavour, almost all the starch present has been converted into fruit sugars and some flesh softening has occurred. While developmental events that occur prior to full bloom are significant in the developmental program leading to the final fruit, samples prior to full bloom were not considered in this work. RNA was extracted from samples from both replicates, labelled and hybridized to an array of 15726 oligonucleotides (45-55 bases long) designed from 15145 unigenes representing approximately 13000 genes. All samples were compared (using a dye swap design) to genomic DNA (gDNA) as a common reference, making samples directly comparable, the absolute expression of all the samples is shown in Additional file 1.

\section{Four major groups of co-ordinately expressed genes during fruit development}

To examine global changes in gene expression, 8719 genes which changed in expression during fruit development (genes with greater than 5-fold change were excluded in order to see the pattern from genes exhibiting smaller changes, inclusion of these genes did not alter the pattern of expression seen for the majority of genes) were grouped using hierarchical clustering and visualized by plotting expression in 3-dimensional space (Figure 2A and $2 \mathrm{~B}$ ). This global analysis of the microarray shows four major patterns of coordinated gene expression. A group of genes was identified with expression in floral buds but are down-regulated throughout fruit development, a second group of genes was up-regulated early in development and down-regulated later, two additional groups of genes were up-regulated during the middle stages of development and during ripening. By contrast with the results seen for tomato [13], there was no sharp change in global expression patterns at ripening, but this difference is likely to reflect differences in sampling.

To identify those genes that changed expression significantly, a one way ANOVA (model y = time) was applied to the entire dataset. Using a non-adaptive false discovery rate (FDR) control [26] of 0.01, 1986 features were identified (corresponding to 1955 genes) where gene expression changed significantly during fruit development. Hierarchical clustering identified four groups of genes with similar patterns of expression during fruit development (Figure 2C, and Additional file 1, which lists the entire dataset). The full bloom (FB) cluster contained 314 genes (315 features) with high expression at 0 DAA and then low expression during the rest of fruit development. The early fruit development (EFD) cluster contained 814 genes ( 819 features) where expression peaked between 14 and 35 DAA. The EFD cluster consisted of two weaker subclusters: EFD1, a group of 320 genes (326 features) which had high expression early and then very low expression later in development; and EFD2 a group of 493 genes (493 features) with high expression early and moderate expression later in development. The mid development cluster (MD) contained 168 genes (169 features) with expression peaking at 60 and 87 DAA and low expression at other stages of development. The ripening cluster (R) contains 668 genes ( 681 features) with expression low initially and eventually peaking late in fruit development. The $\mathrm{R}$ cluster could be clustered into three further subclusters: R1 70 genes (70 features) where expression peaked at harvest ripe (132 DAA) and was low at other stages of development; R2 191 genes (195 features) where expression was very low throughout development until tree ripe (146 DAA); and R3 406 genes (408 features) where expression peaked at tree ripe (146 DAA) but some expression was present at earlier stages of development. Both approaches to clustering identified four major groups of co-ordinately expressed genes suggesting these correspond to major phases of fruit development.

\section{Validation of microarray expression by quantitative $R T$ - PCR}

To examine the reliability of gene expression patterns identified from the microarray we used quantitative 

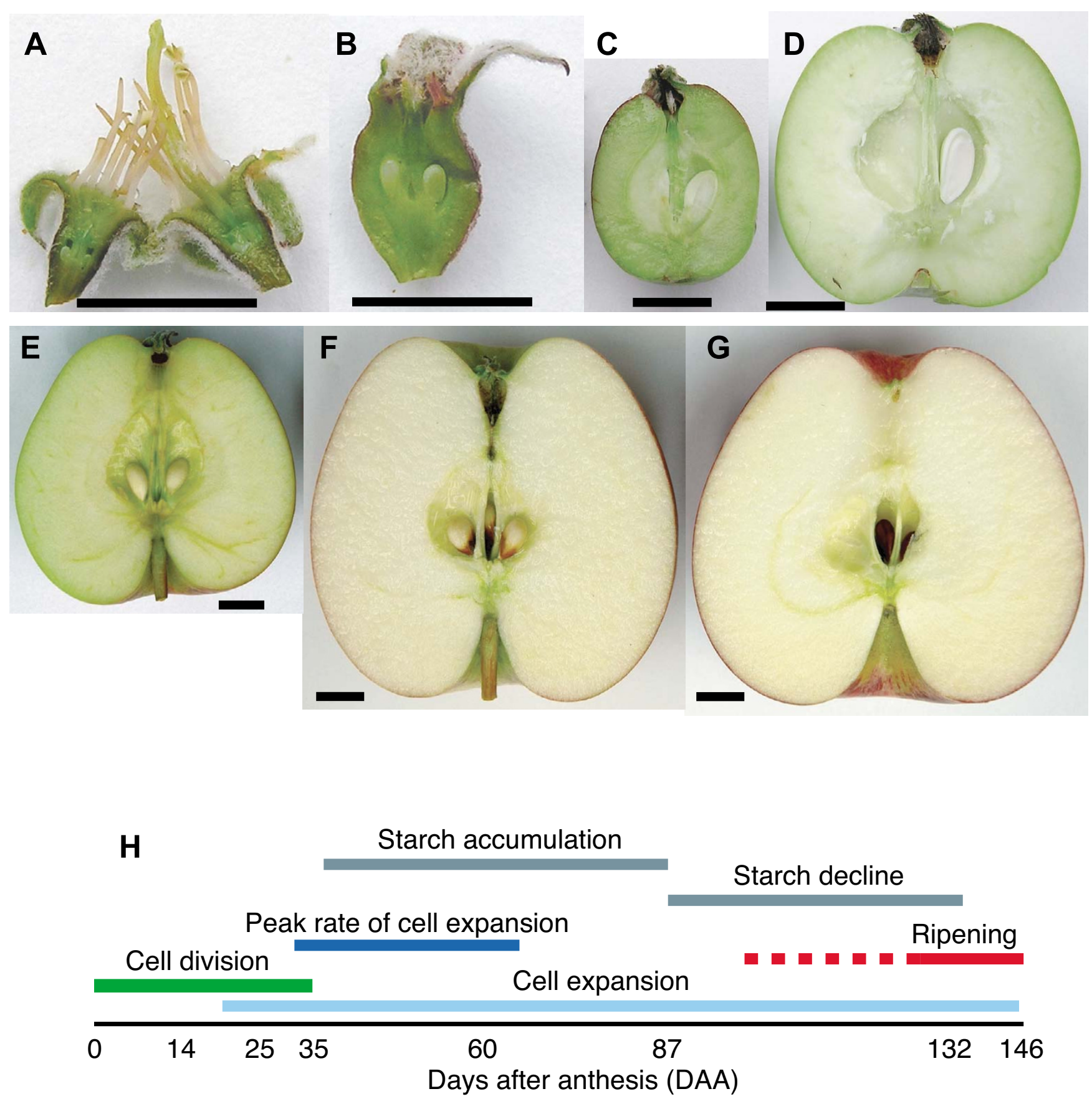

Figure I

Apple fruit development. Apple fruit at various stages of development. A, 0 DAA, B, I4 DAA, C, 35 DAA, D, 60 DAA, E, 87 DAA, F, I 32 DAA, G, I46 DAA. H, diagram of fruit development showing the timing of major physiological events and the sampling time points, adapted from [17-19]. Ripening is shown as a solid and dashed red, solid from the time of the climacteric and dashed for events prior to the climacteric. Bar $=\mathrm{I} \mathrm{cm}$.

reverse transcriptase-PCR (qRT-PCR) to examine steadystate RNA levels during fruit development. Genes for qRTPCR were initially selected from the list of genes that significantly changed their expression during fruit development. The list of regulated genes was ordered from most significant to least significant and genes for qRT-PCR selected at regular intervals from this list (approximately every $50^{\text {th }}$ gene). Several genes were also chosen for qRTPCR to confirm expression patterns of genes in particular pathways (see below). Three housekeeping genes were 


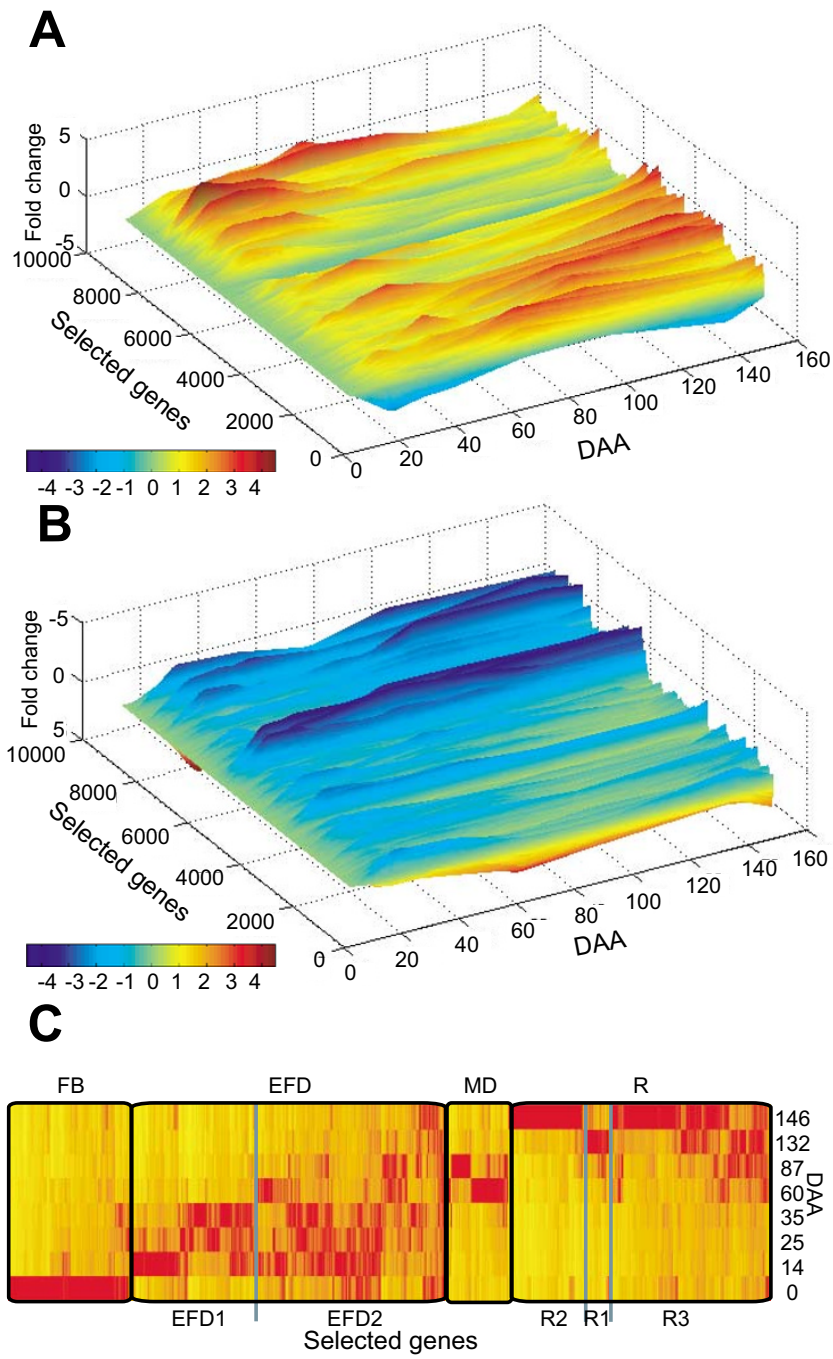

Figure 2

Clustering of genes changing during fruit development. Cluster analysis of gene expression. A and B, Expression patterns for the whole array were clustered and then plotted in 3-D space (MATLAB, version 6.0; The Mathworks). Genes with no expression changes or with greater than 5 fold changes were excluded, leaving 8719 genes. $y$-axis shows fold change. C, The 1955 developmentally regulated genes selected by ANOVA (FDR = 0.0I) were clustered by their geometric means. Vertical lines represent transcript level observed for each EST from 0 to I46 DAA, minimum expression (yellow), maximum (red). Major clusters are: floral bud or full bloom (FB); early fruit development (EFD); mid-development (MD); and ripening (R). The EFD and $R$ clusters were further sub-clustered and indicated by EFDI, EFD2, RI, R2 and R3.

used to normalize qRT-PCR results: an actin gene (Gen-

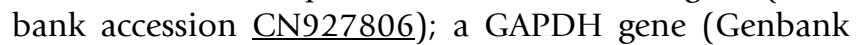
accession $\mathrm{CN}$ 929227) and a gene of unknown function which was selected on the basis of low variability in microarray experiments (Genbank accession CN908822). qRT-PCR expression profiles were compared with microarray expression profiles (Figure 3 ) and scored as matching if they agreed at all developmental stages or if the majority of stages were in agreement and the significant changes in expression also agreed. By these criteria $74 \%$ (26 out of 35) of genes had the same pattern of expression in the microarray experiment as in the qRT-PCR experiment. Interestingly no relationship was observed between the reproducibility of the expression pattern and the significance of the microarray data as determined by ANOVA.

\section{Genes in different functional classes are expressed at different times during fruit development}

To examine the changes in gene function that were occurring during fruit development, functional classes for the apple genes were identified using the Arabidopsis protein function classification defined by the Munich Information center for Protein Sequences (MIPS, using the funcat1.3 scheme [27]). For all the apple genes represented on the array, the Arabidopsis gene with the best sequence similarity based on BLAST analysis was selected [28], with a threshold expect value of $1 \times e^{-5}$, and MIPS functional categories for that Arabidopsis gene assigned to the apple gene. This relatively non-stringent threshold was chosen in order to obtain functional classifications for the majority of apple genes on the array. Table 1 shows the number of apple genes, the number of genes with Arabidopsis matches, the number of matches to unique Arabidopsis genes and the number of MIPS functional categories for the entire array, for the 1986 features selected as changing during fruit development, and for the clusters and subclusters.

The distribution of functional categories for the entire array is shown in Table 2 and compared with the distribution of the 1955 genes selected as changing significantly during fruit development, the major clusters and the subclusters. The distribution of MIPS functional categories changes between the whole array and the genes selected as changing during fruit development suggest that the genes selected are not a random selection from the array as a whole. For example, there appears to be a higher representation of genes associated with metabolism in the fruit development genes (20.3\% vs $16.1 \%$ for the whole array) suggesting developing fruit are more active metabolically. Interestingly, there is a slight increase in the unclassified category in the selected fruit development genes $16.7 \%$ vs $15.7 \%$ for the whole array, while in the ripening cluster the unclassified category is under-represented compared to other clusters (15.2\% vs 17.4 to $17.8 \%$ ), which may reflect the amount of research focused on identifying and characterizing genes involved in the late stages of ripening as compared with early events in fruit development. 

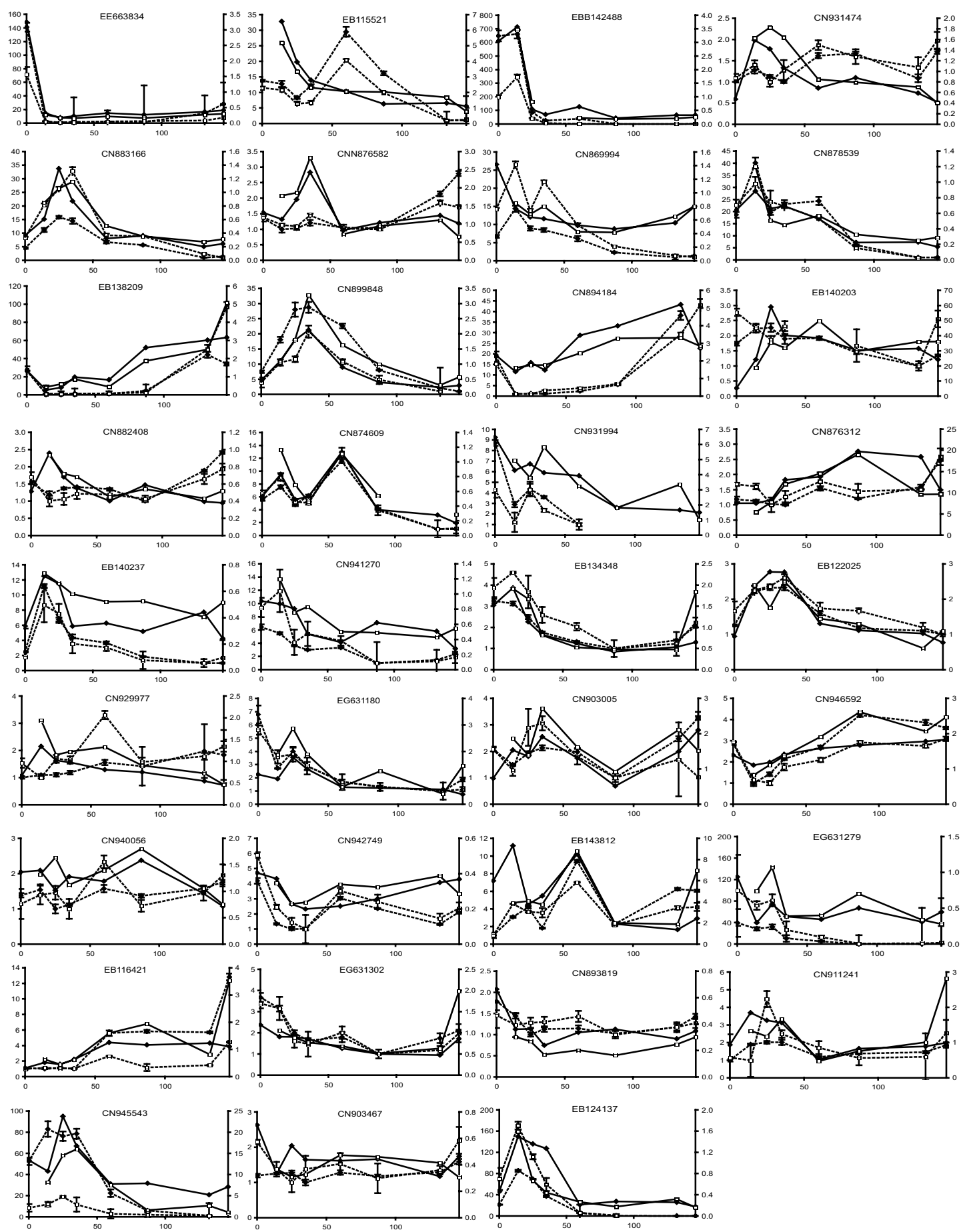

\section{Figure 3}

Validation of array expression patterns. The pattern of expression for a selection of ESTs was confirmed by quantitative RT-PCR using primers designed close to the array oligo. Graphs show transcript levels from the array (solid lines) for Rep I (filled diamonds) and Rep2 (open squares) compared with transcript levels from qRT-PCR (dashed lines, mean and standard error for each sample) for RepI (filled diamonds) and Rep2 (open squares). $X$ axes show DAA, the left $Y$ axes show relative qRT-PCR expression, the right $Y$ axes show absolute array expression. The genbank accession is shown for each EST. 
Table I: Distribution of array features

\begin{tabular}{lccccc}
\hline Subset/cluster $^{\mathrm{a}}$ & ESTs $^{\mathrm{b}}$ & Apple genes $^{\mathrm{c}}$ & Apple genes with hit to Arabidopsis $^{\mathrm{d}}$ & Unique Arabidopsis genes $^{\mathrm{e}}$ & Functional categories $^{f}$ \\
\hline whole array & 15726 & 15145 & 11949 & 8256 & 63732 \\
Selected 1986 & 1983 & 1955 & 1442 & 225 & 7523 \\
FB & 315 & 314 & 603 & 212 & 1141 \\
EFD & 819 & 812 & 126 & 566 & 3042 \\
MD & 169 & 168 & 495 & 124 & 653 \\
R & 681 & 668 & 236 & 474 & 220 \\
EFDI & 326 & 320 & 368 & 356 & 1128 \\
EFD2 & 493 & 493 & 54 & 53 & 1916 \\
RI & 70 & 70 & 154 & 154 & 300 \\
R2 & 195 & 191 & 284 & 277 & 885 \\
R3 & 408 & 406 & & 1552 \\
\hline
\end{tabular}

The table shows the number of genes on the whole array and within the clusters as well as the number of Arabidopsis homologues and the number of MIPS function classifications identified.

a FB = full bloom; EFD = Early fruit development; MD = Mid-development; R = ripening; RI, R2, R3 = Ripening subclusters I, 2 and 3; EFDI, EFD2

$=$ early fruit development subclusters I and 2 .

b The number of apple ESTs represented by the features on the array.

c The number of apple genes, tentative contigs or singletons identified by the ESTs on the array.

d Apple genes were compared with the Arabidopsis predicted protein set using BLASTx to identify similar Arabidopsis genes, the best match (with expect value better than $I \times \mathrm{e}^{-5}$ ) was used for subsequent functional analysis.

e The number of unique Arabidopsis genes identified by BLASTx using the apple genes, in many cases multiple apple genes had strongest similarity to the same Arabidopsis gene, thus fewer Arabidopsis genes were identified than apple genes.

f Functional categories found for the Arabidopsis genes were identified using the MIPS dataset funcat I.3.

Within the four major clusters, the genes with peak expression in mid-development have a reduced representation of genes associated with metabolism $(17.2 \%$ vs 20.1 to $21.5 \%$ ) suggesting this stage of fruit development might be less metabolically active or use fewer different metabolic genes. In contrast, cellular transport and transport mechanism functions are more highly represented in the mid-development cluster ( $2.6 \%$ vs 1.6 to $1.8 \%)$ at the time when fruit are taking up nutrients and water most rapidly.

Control of cellular organization functions are represented more in the EFD and MD clusters $3.8 \%$ and $4.6 \%$ vs $\mathrm{FB} 2.7 \%$ and $\mathrm{R} 2.4 \%$ ) consistent with this period being a stage of fruit development where the structure of the fruit cells is changing rapidly. In the ripening cluster there is an over-representation of genes in the "energy" category $(4.5 \%)$ with the lowest representation in mid-development $(2.1 \%)$. In addition the R2 (peak expression at tree ripe) sub-cluster is over-represented (compared with the other ripening sub-clusters, R1 and R3) in the "metabolism" category (25.4\% vs 21.7 and $18.4 \%$ ) correlating with changes in energy and metabolism during late ripening.

One feature of note was the higher proportion of genes with a cell cycle classification in the EFD cluster (FB 1.8\%, EFD 3.4\%, MD 1.4\%, R 1.9\%). The EFD cluster contains genes for which expression peaks in the first 30 days of fruit development, the stage of development when cells are dividing $[17,18]$. This developmental period involves the division of specific cells to form the final apple fruit shape and since there appeared to be an increase in cell cycle associated genes during this period we identified the genes associated with the cell cycle classification for each cluster (FB 17 genes, EFD 61 genes, MD 8 genes, R 42 genes) and their annotations (Table 3 ). These lists are likely to include those genes important in the regulation of fruit size and shape. For example, analysis of these lists identified three core cell cycle genes (see below), which will be the focus of future research.

\section{Expression of core cell cycle genes}

From morphological studies apple fruit cells go through at least four rounds of cell division during the first 30 days after pollination with total cell number increasing 10 fold $[17,18]$. At around 30 DAA the cells that make up the core and cortex of the mature fruit stop dividing and the rate of cell expansion increases. The control of cell division and cell expansion is a key part of the developmental regulation of fruit and is likely to affect final fruit size as well as texture and the balance between tissue types.

Using an analysis of the Arabidopsis genome sequence, Vanderpoele et al. [29] identified 61 core cell cycle genes; this list has been expanded to 88 genes, including several previously unrecognized groups [30]. Expression analysis in Arabidopsis has demonstrated that many of these core cell cycle genes have regulated steady state RNA levels [30]. To determine if any of these core cell cycle genes were regulated in fruit development, we identified apple homologues and examined their expression. As fruit sam- 
Table 2: Functional classification

\begin{tabular}{|c|c|c|c|c|c|c|c|c|c|c|c|c|}
\hline & Mips code ${ }^{a}$ & Whole arrayb & selected & FB & EFD & MD & $\mathrm{R}$ & EFDI & EFD2 & RI & $\mathrm{R} 2$ & R3 \\
\hline Metabolism & I & 16.1 & 20.3 & 21.5 & 20.1 & 17.2 & 20.9 & 18.3 & 21.1 & 21.7 & 25.4 & 18.4 \\
\hline Energy & 2 & 2.9 & 3.4 & 3.0 & 2.8 & 2.1 & 4.5 & 2.2 & 3.1 & 3.0 & 5.0 & 4.4 \\
\hline Cell Cycle and DNA processing & 3 & 2.9 & 2.5 & 1.8 & 3.4 & 1.4 & 1.9 & 3.3 & 3.5 & 0.7 & 1.9 & 2.4 \\
\hline Transcription & 4 & 5.2 & 4.1 & 4.3 & 4.1 & 4.1 & 3.9 & 4.4 & 4.0 & 3.3 & 3.1 & 4.6 \\
\hline Protein synthesis & 5 & 2.0 & 1.7 & 1.5 & 1.6 & 1.8 & 2.0 & 1.5 & 1.6 & 2.7 & 0.7 & 2.6 \\
\hline Protein fate & 6 & 6.6 & 5.4 & 4.6 & 5.0 & 5.5 & 6.0 & 4.5 & 5.3 & 4.0 & 4.7 & 7.1 \\
\hline Cellular transport \& mechanisms & 8 & 2.4 & 1.7 & 1.8 & 1.6 & 2.6 & 1.7 & 2.1 & 1.3 & 0.7 & 1.7 & 1.8 \\
\hline Cellular comm/signaling & 10 & 6.4 & 5.6 & 6.5 & 5.5 & 5.1 & 5.6 & 5.9 & 5.4 & 9.0 & 5.6 & 4.9 \\
\hline Cell rescue, defense \& virulence & II & 3.6 & 4.0 & 4.1 & 4.1 & 4.6 & 3.6 & 3.3 & 4.6 & 5.7 & 4.3 & 2.9 \\
\hline $\begin{array}{l}\text { Regulation of/interaction with cellular } \\
\text { environment }\end{array}$ & 13 & I.7 & 1.6 & 2.1 & 1.7 & 2.8 & I.I & 1.7 & 1.7 & 0.3 & I.I & 1.3 \\
\hline Cell fate & 14 & 3.2 & 2.6 & 2.3 & 2.5 & 1.5 & 3.2 & 2.4 & 2.6 & 3.7 & 2.6 & 3.3 \\
\hline $\begin{array}{l}\text { Systemic regulation of/interaction with } \\
\text { environment }\end{array}$ & 20 & I.I & 1.3 & 1.5 & 1.3 & I.I & I.I & 1.9 & 0.9 & 1.3 & I.I & I.I \\
\hline Development & 25 & 1.0 & 1.2 & 1.2 & 1.4 & I.I & 0.9 & 1.2 & 1.5 & 2.0 & 0.6 & 0.8 \\
\hline $\begin{array}{l}\text { Transposable elements, viral and plasmid } \\
\text { proteins }\end{array}$ & 29 & 0.1 & 0.1 & 0.1 & 0.0 & 0.0 & 0.1 & 0.0 & 0.1 & 0.0 & 0.2 & 0.0 \\
\hline Control of cellular organisation & 30 & 2.7 & 3.2 & 2.7 & 3.8 & 4.6 & 2.4 & 4.8 & 3.3 & 2.7 & 2.3 & 2.4 \\
\hline Subcellular localisation & 40 & 19.1 & 18.1 & 15.9 & 17.4 & 19.8 & 19.2 & 17.5 & 17.4 & 16.0 & 18.0 & 20.5 \\
\hline Protein activity regulation & 62 & 0.0 & 0.1 & 0.2 & 0.1 & 0.0 & 0.0 & 0.2 & 0.1 & 0.0 & 0.0 & 0.0 \\
\hline $\begin{array}{l}\text { Protein with binding function or cofactor } \\
\text { requirement }\end{array}$ & 63 & 3.2 & 2.9 & 2.7 & 2.8 & 4.4 & 2.8 & 2.3 & 3.1 & 2.3 & 3.1 & 2.7 \\
\hline Storage protein & 65 & 0.1 & 0.0 & 0.1 & 0.0 & 0.0 & 0.0 & 0.1 & 0.0 & 0.0 & 0.1 & 0.0 \\
\hline Transport facilitation & 67 & 3.9 & 3.6 & 4.4 & 3.2 & 2.9 & 3.7 & 3.4 & 3.1 & 3.0 & 4.3 & 3.7 \\
\hline Unclassified & 98 or 99 & 15.7 & 16.7 & 17.8 & 17.4 & 17.5 & 15.2 & 19.1 & 16.4 & 18.0 & 14.2 & I5. \\
\hline
\end{tabular}

The table shows the distribution of classifications as a percentage of the total number of classifications.

a Apple genes for each EST on the array were used to identify Arabidopsis homologues using BLAST with a cutoff of I $\mathrm{e}^{-5}$. Where a putative homologue was identified, the Arabidopsis MIPS (Munich Information centre for Protein Sequences, funcat version I.3) classification(s) for that gene were applied to the apple EST.

b For the whole array, for the features selected as changing during fruit development, and for each of the clusters and sub-clusters the frequency of occurrence for each functional category is shown as a percentage of the total number of functional categories for that cluster (or sub-cluster). $\mathrm{FB}=$ Full bloom; EFD = early fruit development; $M D=$ mid-development; $R=$ ripening; RI, R2, R3 = the 3 ripening sub-clusters; EFDI, EFD2 = the 2

early fruit development sub-clusters.

ples were pooled from multiple fruit and because within a fruit cell division is unlikely to be synchronized, we would not expect to be able to detect variation of expression during the cell cycle. However any core cell cycle gene that varied developmentally might be associated with the control of cell division rates during fruit formation and development.

Thirty-eight apple genes represented on the apple array have strong sequence similarity to the 88 Arabidopsis cell cycle genes identified by Menges et al. [30], using BLASTx and manual examination of protein sequence alignments (31 have expect value of $1 \times \mathrm{e}^{-40}$ or better). Of these 38 apple genes, only three were in the 1955 genes selected by ANOVA as changing significantly during fruit development (Figure 4). ESTs 5126 (Genbank acc. EB107042), 163128 (Genbank acc. CN943384) and 173799 (Genbank acc. EB141951) all had high levels of expression early in development which declined to relatively low levels after 35 DAA. The three genes have sequence similarity to the Arabidopsis genes At2g38620.1, At1g20930.1 and At2g27960 (expect values of $1 \times \mathrm{e}^{-146}, 1 \times \mathrm{e}^{-150}$ and $6 \times \mathrm{e}^{-}$
37, respectively). At2G38620.1 is a CDKB1;2 homologue, At1G20930.1 is a CDKB2;2 homologue and At2g27960 is a CKS1 homologue, the two CDKB genes play roles in progression of the cell cycle and the CKS gene is a mitosis specific scaffold protein. At this level of sequence similarity it is not possible to determine if the apple genes represent orthologues of these genes, although similarity of function is likely.

\section{Expression of genes associated with starch metabolism}

Starch metabolism in apple fruit is a physiological process with a well-defined developmental pattern [19]. However, the mechanism by which starch levels are regulated in plants is complex and little is known about how the activity and turnover of starch synthesis and degradation enzymes are mediated in storage tissues such as fruits (reviewed by Smith et al. [31]). To investigate whether there is some regulation of starch metabolic enzymes at the level of transcription in apple fruit, we examined the patterns of expression for several enzymes involved in starch metabolism. Arabidopsis enzymes involved in starch turnover were identified from the starch and 
Table 3: Annotation of cell cycle genes by cluster

\begin{tabular}{|c|c|c|c|c|}
\hline \multicolumn{5}{|c|}{ FB cluster } \\
\hline EST & Genbank acc. & Best A. thaliana hit ${ }^{\mathrm{a}}$ & e value & Description ${ }^{b}$ \\
\hline 5019 & CN936403 & AT5G44680.I & $\mathrm{le}-40$ & methyladenine glycosylase family protein \\
\hline 5126 & $\underline{\mathrm{EB} I 07042}$ & AT2G38620.I & $9 e-80$ & CDKBI;2 cell division control protein \\
\hline 33679 & CN929052 & AT2G47420.I & $9 e-18$ & dimethyladenosine transferase \\
\hline 59120 & CN862228 & AT5G42320.I & $2 \mathrm{e}-12$ & zinc carboxypeptidase family protein \\
\hline 67405 & $\underline{\mathrm{CN} 864463}$ & AT5G53000.I & $3 e-31$ & protein phosphatase $2 \mathrm{~A}$-associated $46 \mathrm{kDa}$ protein \\
\hline 86932 & $\overline{\mathrm{EB} \mid 19954}$ & ATIG0I490.I & $2 \mathrm{e}-19$ & heavy-metal-associated domain-containing protein \\
\hline 124169 & CN937737 & ATIGI8660.I & $3 e-67$ & zinc finger (C3HC4-type RING finger) family protein \\
\hline $1344 \mid 5$ & CN888558 & AT3G62600.I & $1 \mathrm{e}-153$ & DNAJ heat shock family protein \\
\hline 140667 & CN938500 & AT2G24490.I & $8 e-46$ & replication protein, putative \\
\hline 222173 & CN876164 & AT4GII0I0.I & $9 e-47$ & nucleoside diphosphate kinase 3, mitochondrial (NDK3) \\
\hline 226032 & $\underline{E G 631233}$ & AT3G08500.I & $3 e-48$ & myb family transcription factor (MYB83) \\
\hline 254247 & CN912925 & ATIGI0290.I & $3 e-49$ & dynamin-like protein 6 (ADL6) \\
\hline 256645 & $\underline{E B I 51655}$ & ATIG79350.I & le-77 & EMBII35 DNA-binding protein, putative \\
\hline 257305 & CN908I7I & AT3G57550.I & $3 e-41$ & guanylate kinase 2 (GK-2) \\
\hline 258270 & $\overline{\mathrm{CN} 914773}$ & AT2G30II0.I & le-179 & ubiquitin activating enzyme I (UBAI) \\
\hline 264677 & CN910366 & AT3G48I60.2 & $6 e-68$ & E2F-like repressor E2L3 (E2L3) \\
\hline 264992 & CN917058 & AT5G23430.I & le-53 & transducin family protein/WD-40 repeat family protein \\
\hline
\end{tabular}

EFD cluster

\begin{tabular}{|c|c|c|c|c|}
\hline EST & Genbank acc. & Best A. thaliana hit & e value & Description \\
\hline 12163 & $\underline{\mathrm{EB} 109178}$ & AT3G28030.I & $2 e-27$ & UV hypersensitive protein (UVH3) \\
\hline 14094 & CN931474 & AT2G0I440.I & $6 e-15$ & ATP-dependent DNA helicase, putative \\
\hline 15274 & CN932236 & AT3G25500.I & $8 e-26$ & $\mathrm{FH} 2$ domain-containing protein \\
\hline 19893 & $\overline{\mathrm{CN} 925129}$ & ATIG73540.I & $3 e-11$ & ATNUDT2I MutT/nudix family protein \\
\hline 29516 & EBIIII254 & AT2G39730.I & $9 e-72$ & RuBisCO activase \\
\hline 31066 & CN927871 & AT3G23890.I & $8 e-13$ & DNA topoisomerase II \\
\hline 33027 & CN928590 & AT3G25500.I & $3 e-39$ & $\mathrm{FH} 2$ domain-containing protein \\
\hline 43417 & $\underline{E B} \mid 13579$ & ATIG69770.I & $3 e-06$ & chromomethylase 3 (CMT3) \\
\hline 45185 & CN857495 & AT5G055I0.I & $2 e-25$ & low similarity to SP:O60566 Mitotic checkpoint serine/threonine-protein kinase BUBI $\beta$ \\
\hline 62518 & $\underline{E B I 16342}$ & AT3G08910.1 & $7 e-67$ & DNAJ heat shock protein \\
\hline 64262 & CN850169 & AT2G30200.I & le-l48 & T27EI3_6 \\
\hline 85474 & $\overline{\mathrm{CN} 869267}$ & ATIG68760.I & $6 e-54$ & ATNUDTI MutT/nudix family protein \\
\hline 91885 & CN871666 & ATIGI0520.I & $3 e-15$ & DNA polymerase lambda (POLL) \\
\hline 93419 & CN874495 & AT5G2675I.I & $4 e-58$ & shaggy-related protein kinase $\alpha /$ ASK- $\alpha$ (ASKI) \\
\hline 95093 & $\underline{\mathrm{CN} 875141}$ & AT5GI8II0.I & $5 e-60$ & novel cap-binding protein (nCBP) \\
\hline 105540 & CN886787 & AT3G5I770.I & |e-III & similar to tetratricopeptide repeat (TPR)-containing protein \\
\hline 111728 & $\underline{\underline{E B} 124553}$ & ATIG44900.I & $3 e-50$ & DNA replication licensing factor \\
\hline 118006 & $\overline{\mathrm{EB} \mid 25634}$ & AT2G2I790.I & $8 e-45$ & ribonucleoside-diphosphate reductase small chain, putative \\
\hline 119405 & CN887179 & ATIG680I0.I & $|e-8|$ & glycerate dehydrogenase/NADH-dependent hydroxypyruvate reductase \\
\hline 120390 & $\overline{\mathrm{CN} 890521}$ & ATIG2I660.I & $7 e-12$ & low similarity to SP:OI4976 Cyclin G-associated kinase \\
\hline 138266 & $\overline{\mathrm{CN} 937814}$ & AT2GI7I20.I & $3 e-79$ & peptidoglycan-binding LysM domain-containing protein \\
\hline 142020 & CN939277 & AT2G388I0.I & $2 e-48$ & histone $\mathrm{H} 2 \mathrm{~A}$, putative \\
\hline 142920 & $\underline{E B} 127800$ & AT5G57850.I & $2 e-08$ & aminotransferase class IV family protein \\
\hline 148629 & EBI38792 & AT3G22630.1 & $2 e-36$ & 20 s proteasome $\beta$ subunit $\mathrm{D}$ (PBDI) (PRGB) \\
\hline 149453 & CN897394 & AT5G55230.I & $1 e-118$ & ATMAP65-I Binds and bundles microtubules \\
\hline 149668 & $\overline{\mathrm{CN} 897544}$ & AT4G36080.1 & Ie-103 & FAT domain-containing protein/phosphatidylinositol 3- and 4-kinase family protein \\
\hline 151134 & $\underline{E B} 139596$ & AT2G42580.I & $5 e-24$ & tetratricopeptide repeat (TPR)-containing protein \\
\hline 151602 & CN898773 & AT5GI3780.I & $8 e-81$ & GCN5-related $\mathrm{N}$-acetyltransferase, putative, similar to ARDI subunit \\
\hline 152213 & $\overline{\mathrm{CN} 940414}$ & AT2G35040.I & $1 e-1 \mid 2$ & AICARFT/IMPCHase bienzyme family protein \\
\hline 153604 & $\underline{E B \mid 40203}$ & ATIG55350.I & 0 & EMB 275 calpain-type cysteine protease family \\
\hline 153992 & CN900578 & AT2G21790.I & le- 160 & $\mathrm{RI}$ ribonucleoside-diphosphate reductase small chain, putative \\
\hline 155385 & CN901052 & AT2G21790.I & $2 e-83$ & RI ribonucleoside-diphosphate reductase small chain, putative \\
\hline 155966 & CN901211 & AT5G6I060.I & $2 e-34$ & histone deacetylase family protein \\
\hline 159200 & CN940759 & AT2GI4880.I & $6 e-36$ & SWIB complex BAF60b domain-containing protein \\
\hline 162529 & CN942994 & AT3G44II0.I & $1 \mathrm{e}-152$ & DNAJ heat shock protein, putative (J3) \\
\hline
\end{tabular}


Table 3: Annotation of cell cycle genes by cluster (Continued)

\begin{tabular}{|c|c|c|c|c|}
\hline 163128 & CN943384 & ATIG20930.I & $1 \mathrm{e}-102$ & CDKB2;2 cell division control protein, putative \\
\hline 163154 & CN943405 & AT5G61060.1 & $2 e-84$ & histone deacetylase family protein \\
\hline 166835 & EE663942 & AT3G I7880.I & Ie-58 & tetratricoredoxin (TDX) \\
\hline 170408 & EBI40959 & AT3G08910.I & $7 e-59$ & DNAJ heat shock protein, putative \\
\hline 170963 & CN882668 & AT2G46225.I & $2 e-20$ & ABIILI Encodes a subunit of the WAVE complex \\
\hline 171493 & CN883039 & AT2G29570.I & $|e-|||$ & PCNA2 proliferating cell nuclear antigen 2 (PCNA2) \\
\hline 172325 & CN883596 & AT5G08020.I & $7 e-91$ & similar to replication protein AI (Oryza sativa) \\
\hline 173799 & $\underline{E B|4| 95 \mid}$ & AT2G27960.I & $6 e-37$ & CKSI cyclin-dependent kinase \\
\hline |8073| & CN904791 & ATIG75690.I & $2 e-55$ & chaperone protein dnaJ-related \\
\hline 181072 & CN904980 & AT3GI8I90.I & 0 & chaperonin, putative \\
\hline 184975 & $\underline{E B \mid 48197}$ & AT5G44680.I & le-90 & methyladenine glycosylase family protein \\
\hline 186444 & EBI49644 & AT3G 19420.1 & $2 e-12$ & MLDI4.22 \\
\hline 186960 & EBI50084 & AT3G08690.I & $9 e-27$ & ubiquitin-conjugating enzyme II (UBCII), E2 \\
\hline 213416 & $\underline{E B}|573| 4$ & ATIG62990.I & Ie- 126 & homeodomain transcription factor (KNAT7) \\
\hline 220588 & EBI32350 & AT3G48590.I & $2 \mathrm{e}-15$ & CCAAT-box binding transcription factor Hap5a, putative \\
\hline 220604 & CN948726 & AT4G33260.I & $8 e-17$ & WD-40 repeat family protein \\
\hline 245977 & CN903005 & AT3G26730.I & le-49 & zinc finger ( $\mathrm{C} 3 \mathrm{HC} 4$-type RING finger) family protein \\
\hline 256235 & CN913864 & AT2G31320.I & 0 & NAD $(+)$ ADP-ribosyltransferase, putative \\
\hline 256449 & CN916743 & AT3G22890.I & le- 165 & sulfate adenylyltransferase I/ATP-sulfurylase I (APSI) \\
\hline 257853 & CN914478 & AT5G52640.I & 0 & heat shock protein 8I-I (HSP8I-I) \\
\hline 261756 & CN908391 & AT2G25050.I & $5 e-07$ & formin homology 2 domain-containing protein \\
\hline 264654 & CN910347 & AT5G67100.I & $5 e-87$ & DNA-directed DNA polymerase $\alpha$ catalytic subunit, putative \\
\hline 265667 & CN910570 & AT5GI6270.I & $3 e-06$ & Rad21/Rec8-like family protein \\
\hline $2664 \mid 4$ & $\underline{E B} \mid 52178$ & AT5G400I0.I & |e-II2 & AAA-type ATPase family protein \\
\hline 315707 & CN915704 & ATIG03080.I & $4 e-25$ & kinase interacting family protein \\
\hline 318786 & CN949202 & ATIG04820.I & $4 e-63$ & tubulin $\alpha-2 / \alpha-4$ chain (TUA4) \\
\hline
\end{tabular}

Mid dev cluster

\begin{tabular}{|c|c|c|c|c|}
\hline EST & Genbank acc. & Best A. thaliana hit & e value & Description \\
\hline 109011 & CN880656 & ATIG29400.I & $4 e-77$ & RNA recognition motif (RRM)-containing protein \\
\hline 144884 & CN894104 & ATIG03190.I & le-33 & DNA repair protein/transcription factor protein (UVH6) \\
\hline 146572 & CN895134 & AT2GI5580.I & $2 e-14$ & zinc finger (C3HC4-type RING finger) family protein \\
\hline 167024 & EG631355 & AT5G66770.I & 0 & scarecrow transcription factor family protein \\
\hline 182020 & $\overline{\mathrm{EB} \mid 43575}$ & ATIG69840.I & $3 e-73$ & band 7 family protein \\
\hline 185452 & $\underline{E B \mid 48668}$ & ATIG07350.I & $|e-3|$ & transformer serine/arginine-rich ribonucleoprotein, putative \\
\hline 214774 & CN946063 & ATIG26830.I & le-75 & CUL3 Cullin, putative, similar to Cullin homolog 3 (CUL-3) \\
\hline 268033 & CN918413 & AT5G646I0.I & |e- $\mid 42$ & histone acetyltransferase, putative \\
\hline
\end{tabular}

\section{Ripening cluster}

\begin{tabular}{|c|c|c|c|c|}
\hline EST & Genbank acc. & Best A. thaliana hit & e value & Description \\
\hline 541 & CN934040 & AT3G57220.I & le-113 & UDP-GlcNAc:dolichol phosphate N-acetylglucosamine-I-phosphate transferase, putative, \\
\hline 11629 & $\underline{E B 109003}$ & ATIG34260.I & le-07 & phosphatidylinositol-4-phosphate 5-kinase family protein \\
\hline 15678 & CN932487 & AT5G5I600.I & $3 e-85$ & microtubule associated protein (MAP65/ASEI) family protein \\
\hline 57477 & CN860296 & AT2G44270.I & le-164 & contains Pfam profile PF0II7I: PP-loop family \\
\hline 59442 & CN862410 & ATIG73460.I & le-35 & protein kinase family protein Pfam:PF00069 \\
\hline 64262 & CN850169 & AT2G30200.I & le-148 & expressed protein T27EI3_6 \\
\hline 64821 & CN863160 & AT5G5I570.I & $|e-| 4 \mid$ & band 7 family protein \\
\hline 68274 & CN864737 & AT5G26940.I & $3 e-59$ & exonuclease family protein \\
\hline 89547 & CN873630 & AT3G6II40.I & 2e-09 & COP9 signalosome complex subunit I/CSN complex subunit I \\
\hline 89732 & $\overline{\mathrm{EB} 121320}$ & AT4G 12600.1 & $8 e-18$ & ribosomal protein L7Ae/L30e/SI2e/Gadd45 family protein \\
\hline 93568 & CN874587 & AT3G I0940.I & le-108 & similar to protein phosphatase PTPKISI protein \\
\hline 107778 & $\overline{\mathrm{CN} 871562}$ & ATIG77600.I & $6 e-07$ & expressed protein, weak similarity to Pds5 \\
\hline 111901 & $\overline{\mathrm{CN} 879476}$ & ATIGI4400.I & le-39 & ubiquitin-conjugating enzyme I (UBCI), E2 \\
\hline 130406 & CN891639 & AT3G27I80.I & $5 e-08$ & expressed protein MYF5.5 \\
\hline 132758 & CN892125 & AT5G48330.I & $9 e-55$ & regulator of chromosome condensation $(\mathrm{RCCl})$ family protein \\
\hline 134470 & CN888599 & AT2G29900.I & $2 e-35$ & presenilin family protein \\
\hline 141926 & CN939221 & AT5G50960.I & le-163 & similar to Nucleotide-binding protein I (NBP I) \\
\hline 143463 & CN890171 & ATIG69670.I & $9 e-75$ & ATCUL3B cullin, putative \\
\hline
\end{tabular}


Table 3: Annotation of cell cycle genes by cluster (Continued)

\begin{tabular}{|c|c|c|c|c|}
\hline 146658 & CN895184 & AT5GI2200.1 & 0 & dihydropyrimidinase (PYD2) \\
\hline 147359 & $\underline{E B} 138102$ & ATIG059I0.I & Ie-III & cell division cycle protein 48-related/CDC48-related \\
\hline $1474 \mid 8$ & CN895629 & AT3GI8600.I & $4 e-32$ & DEAD/DEAH box helicase, putative \\
\hline 150678 & CN898212 & AT3G07760.I & $3 e-28$ & expressed protein MLP3.2I \\
\hline 155382 & CN901049 & AT3G24320.I & $3 e-73$ & DNA mismatch repair MutS family (MSHI) \\
\hline 159868 & $\underline{E B I 28540}$ & AT2GI9770.I & $5 e-45$ & profilin 4 (PRO4) (PFN4) \\
\hline 172304 & CN883582 & AT3G48530.I & $2 e-72$ & CBS domain-containing protein \\
\hline 175286 & CN904072 & AT4G25I30.I & $1 \mathrm{e}-100$ & peptide methionine sulfoxide reductase, putative \\
\hline 184340 & $\underline{E B \mid 47575}$ & AT3GI3230.I & 2e-77 & expressed protein MDCII.5 \\
\hline 185727 & $\underline{E B} \mid 48939$ & AT5G21990.I & le- 107 & tetratricopeptide repeat (TPR)-containing protein \\
\hline 186037 & $\underline{\mathrm{EB}} 449246$ & AT4G25I30.I & $3 e-7 \mid$ & peptide methionine sulfoxide reductase, putative \\
\hline 216840 & CN947326 & AT4G04955.I & $3 e-45$ & ATALN Encodes an allantoinase \\
\hline 219785 & CN851874 & AT2G30200.I & le-148 & expressed protein T27E13_6 \\
\hline 221777 & CN875931 & AT5GI7570.I & le-1I5 & tatD-related deoxyribonuclease family protein \\
\hline 221885 & $\underline{E B} \mid 22552$ & ATIG55860.I & $2 \mathrm{e}-19$ & ubiquitin-protein ligase I (UPLI) \\
\hline 225203 & CN877466 & ATIG68370.I & $9 e-74$ & gravity-responsive protein (ARGI) \\
\hline 228881 & CN878128 & ATIG77930.I & le- 105 & DNAJ heat shock $\mathrm{N}$-terminal domain-containing protein \\
\hline 229438 & CN87827I & ATIG20760.I & $2 e-30$ & calcium-binding EF hand family protein \\
\hline 229922 & CN878558 & ATIG20II0.I & $4 e-73$ & zinc finger (FYVE type) family protein \\
\hline 257846 & CN91447I & ATIGI5240.I & $8 e-26$ & phox (PX) domain-containing protein \\
\hline 266842 & CN916307 & AT2G45620.I & $4 \mathrm{e}-09$ & nucleotidyltransferase family protein \\
\hline 267005 & CN916212 & AT4G28000.I & $7 e-51$ & AAA-type ATPase family protein \\
\hline 267748 & $\overline{\mathrm{CN} 918233}$ & AT5G4I370.I & $4 e-13$ & XPBI involved in both DNA repair and transcription \\
\hline 289972 & CN884487 & AT3G23610.I & $5 e-60$ & dual specificity protein phosphatase (DsPTPI) \\
\hline
\end{tabular}

a ESTs that change during fruit development were used to identify apple genes and the best Arabidopsis homolog (by BLAST) was found for that apple gene. Where a sequence similarity was better than I $\times$ e-5 the MIPS functional category for that Arabidopsis gene was determined. $b$ Genes with the functional category "Cell cycle and DNA processing" were identified in each array cluster and ESTs in those clusters and the annotation of the Arabidopsis homolog is shown.

sucrose metabolic pathway in the Kyoto Encyclopedia of Genes and Genomes (KEGG) database [32]. Apple genes with significant sequence similarity to the Arabidopsis starch turnover genes (BLAST significance better than $1 \times$ $\mathrm{e}^{-100}$ ) were included in the analysis (Table 4).

Genes which had constant expression during apple fruit development, and hence did not show transcriptional regulation in this developmental process were not studied further. Those with low-level expression were also excluded due to the high variability observed where the targets have low signal intensity on the microarray. $\alpha$ amylase is one example of an enzyme for which the transcript level detected was below the cut off value and consequently was not analysed further. In total, ESTs for 15 apple genes with homology to starch metabolic enzymes were identified with microarray expression profiles that varied during fruit development (Table 4) and qRT-PCR was performed to confirm these profiles. For nine of the 15 enzymes, the qRT-PCR analysis produced expression profiles that strongly supported the patterns seen in the microarray data (Figure 5). For the remaining six enzymes the qRT-PCR pattern differed from the microarray pattern possibly because the RT-PCR primers were amplifying different alleles or genes than those detected by the microarray oligo.
Four distinct expression profiles were observed: I) for a $\beta$ amylase gene (EB114557), transcript levels were high at anthesis and low for the rest of fruit development, sucrose synthase ( $\underline{\mathrm{CN} 897963})$ had a similar pattern of expression although with a less rapid decline in expression; II) for sucrose phosphatase (EB156512) and a sucrose-phosphate synthase gene (EB123469), transcript levels peaked at the earliest and latest time points; III) for ADP-glucose phosphorylase ( $\mathrm{CN884033}$ ) and UDP-glucose pyrophosphorylase (EG631379), transcript levels were lowest in the bud and increased during fruit development to reach a maximum in tree ripe apple; IV) for an $\alpha$-glucosidase (EE663791) and a starch synthase (EB121923) transcript levels were low both early and late in apple development and peaked during early and mid development, respectively.

Microarray data can potentially be used to identify regulatory genes associated with coordinating expression of pathways such as starch metabolism. The similarity of the profiles for sucrose phosphatase and sucrose-phosphate synthase (Figure 5) suggested coordination of expression. Using cluster analysis, a single domain Myb transcription factor (EB129522) was identified with a similar expression pattern to sucrose phosphatase and sucrose-phosphate synthase. Preliminary transient expression studies in Nicotiana benthamiana leaves did not show activation of 


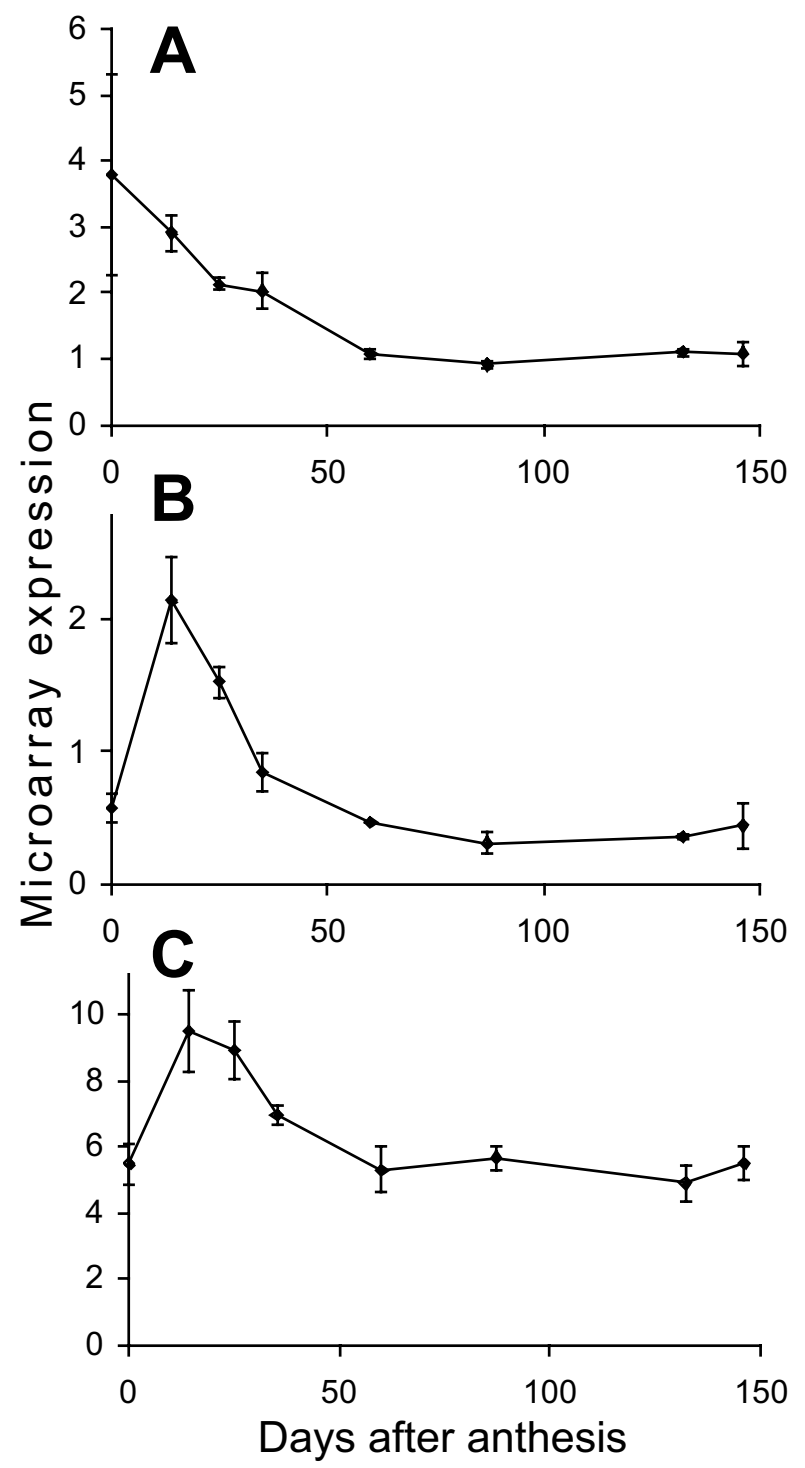

\section{Figure 4}

Expression of core cell cycle genes. Array expression levels are shown for the three core cell cycle genes that changed significantly during apple fruit development. $A$, EBI 07042 a CDKBI;2 homologue, B, CN943384 a CDKB2;2 homologue, C, EBI4I95I a CKSI homologue.

promoter regions of the two starch metabolic genes using this Myb gene alone (data not shown). Further analysis using larger promoter regions and possible binding partners for the Myb protein may identify a regulatory role for this gene.

\section{Expression of candidate fruit development genes in apple} While Arabidopsis does not produce a large fleshy fruit and the post-pollination development of the fruiting body is limited, the availability of excellent genetic resources and genomic tools such as a complete genome sequence and whole genome microarrays has allowed identification of many important genes involved in floral and fruit development. The development of floral organs and the genes involved in production of mature carpels prior to fertilization have been the subject of several reviews [33]. Post-pollination development of the Arabidopsis fruit is limited, and while it serves as a good model for dehiscent fruit, it is not clear whether the genes involved in Arabidopsis fruit development are important in the development of fleshy fruit. In spite of this reservation, the importance of transcription factors such as agamous, fruitful, AGL1/AGL5, spatula, crabs claw, and ettin in specification of carpel identity and silique development suggests that transcription factors such as these may play significant roles in the development of fleshy fruit [33]. BLAST searches identified apple genes that had oligos on the apple microarray for a spatula homologue (At4g36930, apple EST289091 Genbank acc EB132541, expect value $8 \times \mathrm{e}^{-41}$ ); ettin/ARF3 (At2g33860, apple EST250932, Genbank acc $\underline{\mathrm{CN} 911459}$, expect value $1 \times \mathrm{e}^{-}$ 163); a fruitful/AGL8 homologue (At5g60910, apple EST158712, Genbank acc EE663894, expect value $7 \times \mathrm{e}^{-60}$ ) and a crabs claw homologue (most homologous to yabby5 At2g26580, apple EST111296, Genbank acc EB124712, expect value $3 \times \mathrm{e}^{-42}$ ) and expression patterns for these genes were plotted (Figure 6 ). The expression of the fruitful/AGL8 homologue (Figure 6C), which has more similarity to AP1 than fruitful, increases at the time when apple fruit are enlarging (and down-regulated during cell division) which is interesting given the short compact silique of the fruitful mutant.

\section{Comparison of apple and tomato fruit development}

A recent study by Alba et al. [13] used an array of 12899 EST clones representing 8500 tomato genes to examine fruit development and ripening, with a particular focus on the events occurring around ripening. While this study did not include floral buds or the stages of tomato development, where cell division is most active, it is the most complete fruit development data set to date. In order to identify genes involved in both apple and tomato fruit development, we used the list of genes that change during tomato fruit development to find apple genes on our microarray.

Using MegaBLAST (word size 12, threshold $1 \times \mathrm{e}^{-5}$ ) the list of 869 genes that change during tomato fruit development from Alba et al. [13] was used to identify homologous apple genes that were present on the array used in this work. Three hundred and thirty-six unique tomato genes had homology to 479 unique apple genes by these criteria. Of these apple genes, 102 were identified as having significant changes in expression during apple fruit development and hence are transcriptionally regulated in 
Table 4: Enzymes involved in Starch metabolism

\begin{tabular}{|c|c|c|c|c|c|c|}
\hline Enzyme & EC \# & A. thaliana gene & Genbank acc. ${ }^{a}$ & expect valueb & qPCR vs arrayc & Localisation \\
\hline \multirow[t]{5}{*}{ Sucrose synthase } & 2.4 .1 .13 & At3g43190 & $\underline{E B|44| 94}$ & 0 & + & plastidic \\
\hline & & At4g02280 & $\overline{\mathrm{CN} 897963}$ & 0 & ++ & unknown \\
\hline & & At5g20830 & & & & \\
\hline & & At5g37180 & & & & \\
\hline & & At5g49190 & & & & \\
\hline UDP-glucose pyrophosphorylase & 2.7.7.9 & At5gl7310 & $\underline{E G 631379}$ & le-173 & +++ & endomembrane system \\
\hline \multirow[t]{2}{*}{ Starch synthase } & 2.4 .1 .21 & Atg $\lg 32900$ & EE663720 & 0 & - & plastidic \\
\hline & & At3g0II 80 & $\mathrm{~EB} \mid 21923$ & 0 & +++ & plastidic \\
\hline \multirow[t]{6}{*}{ ADP-glucose phosphorylase } & 2.7.7.27 & Atlg27680 & CN884033 & le- 167 & +++ & plastidic \\
\hline & & At2g21590 & & & & \\
\hline & & At4g39210 & & & & \\
\hline & & At5g 19220 & & & & \\
\hline & & At5g48300 & & & & \\
\hline & & Atlg05610 & & & & \\
\hline \multirow[t]{2}{*}{ Starch phosphorylase } & 2.4.1.1 & At3g29320 & EE663644 & 0 & - & plastidic \\
\hline & & At3g46970 & $\underline{E B 108842}$ & le-II5 & - & unknown \\
\hline \multirow[t]{4}{*}{ Sucrose-phosphate synthase } & 2.4 .1 .14 & At5g20280 & $\underline{E B I} 12628$ & 0 & ++ & unknown \\
\hline & & Atlg04920 & EBI23469 & 0 & ++ & unknown \\
\hline & & At5g 11110 & & & & \\
\hline & & At4gI0I20 & & & & \\
\hline \multirow[t]{2}{*}{$\beta$-amylase } & 3.2.1.2 & At4gI5210 & $\underline{E B} \mid 14557$ & $1 e-116$ & +++ & plastidic \\
\hline & & At4g 17090 & EG631202 & le- 104 & - & plastidic \\
\hline \multirow[t]{3}{*}{$\alpha$-glucosidase } & 3.2 .1 .20 & At3g45940 & EE663791 & 0 & +++ & endomembrane system \\
\hline & & At5gl I720 & EE663790 & 0 & - & endomembrane system \\
\hline & & At5g63840 & & & & \\
\hline Sucrose phosphatase & 3.1 .3 .24 & At2g35840 & $\underline{E B I 56512}$ & 0 & +++ & cytoplasm \\
\hline
\end{tabular}

Starch metabolism genes were identified and the expression of putative apple starch metabolism genes confirmed by qRT-PCR.

a The representative EST on the array is shown for the best apple gene match to the Arabidopsis gene.

$b$ The significance of the BLAST comparison between the Arabidopsis gene and the best apple gene.

c The degree of correspondence between pattern of gene expression by microarray and the pattern by qPCR. $-=$ no correspondence; $+=$ more

than two points of divergence; $++=$ good correspondence but some differences; $+++=$ strong correspondence

both apple and tomato. We further filtered the list to include only those genes in the apple EFD (41 genes), $\mathrm{MD}$ (16 genes) and R (35 genes) clusters (Table 5). An additional 10 apple genes in the FB cluster were also identified by homology with the developmentally regulated tomato genes but not examined further since the tomato microarray did not include a floral bud sample.

The expression data from both the apple and tomato microarrays was plotted for several of the genes identified. The top five genes in each cluster by quality of the BLAST match between apple and tomato were plotted. Several genes possibly involved in processes occurring during early fruit development, mid development and ripening were also plotted. And because microarrays have the potential to identify genes involved in processes without prior information, all the genes without annotation were also plotted.

The development of apple and tomato fruit, from anthesis to mature fruit differs in length, however we compared patterns of expression during similar phases of development, in particular the mid development phase when cells are expanding in both apple and tomato ( 8-35 DAA in tomato and $440-110$ DAA in apple) and the ripening phase ( $40-50$ DAA in tomato and $\sim 130-150$ DAA in apple). Of the 47 genes for which expression patterns were compared, 16 had similar patterns of expression in 


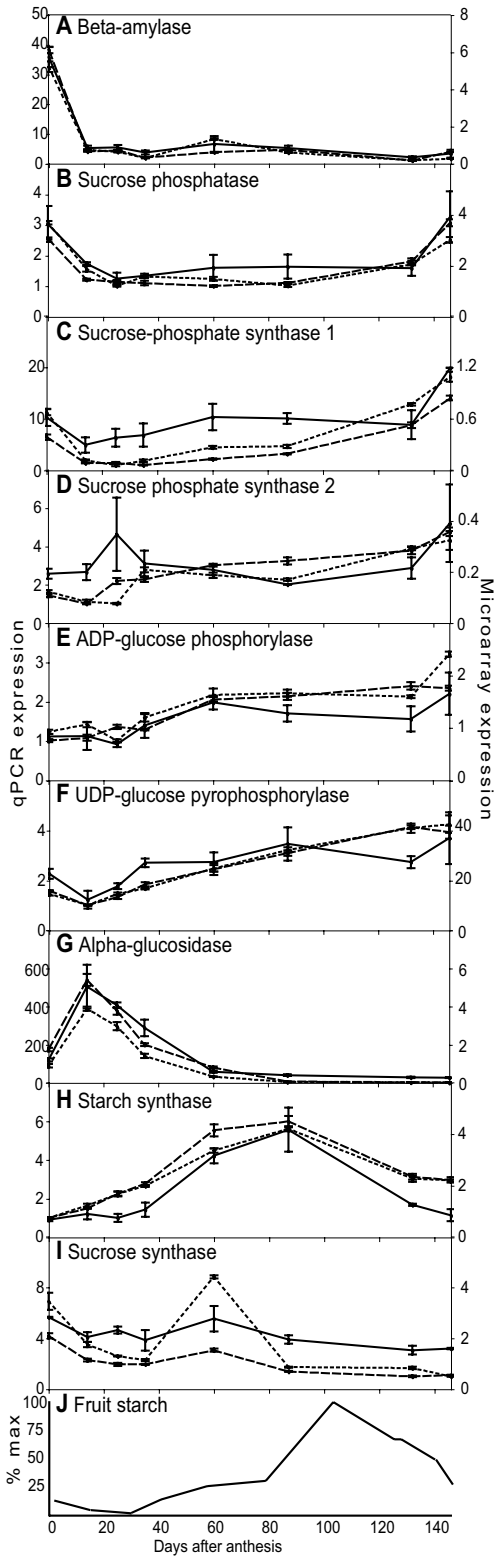

Figure 5

Expression of starch metabolism genes. Starch metabolic enzymes identified from KEGG were used to identify apple homologues. Where apple array expression varied and gave reliable data the expression pattern was confirmed by qRT-PCR. Of the I5 genes validated, 9 showed very similar patterns of expression in both array and qRT-PCR. A to F, The array data for Repl and Rep2 was combined and mean and standard error is plotted (solid lines), qRT-PCR data is shown for each Rep as mean and standard error for qRTPCR replicates, Repl short dashes, Rep2 long dashes. G, Diagram showing fruit starch levels during fruit development as a percentage of the maximum levels, adapted from Brookfield et al. [19]. $X$ axes show DAA, the left $Y$ axes shows relative qRT-PCR expression; the right $Y$ axes shows absolute array expression.
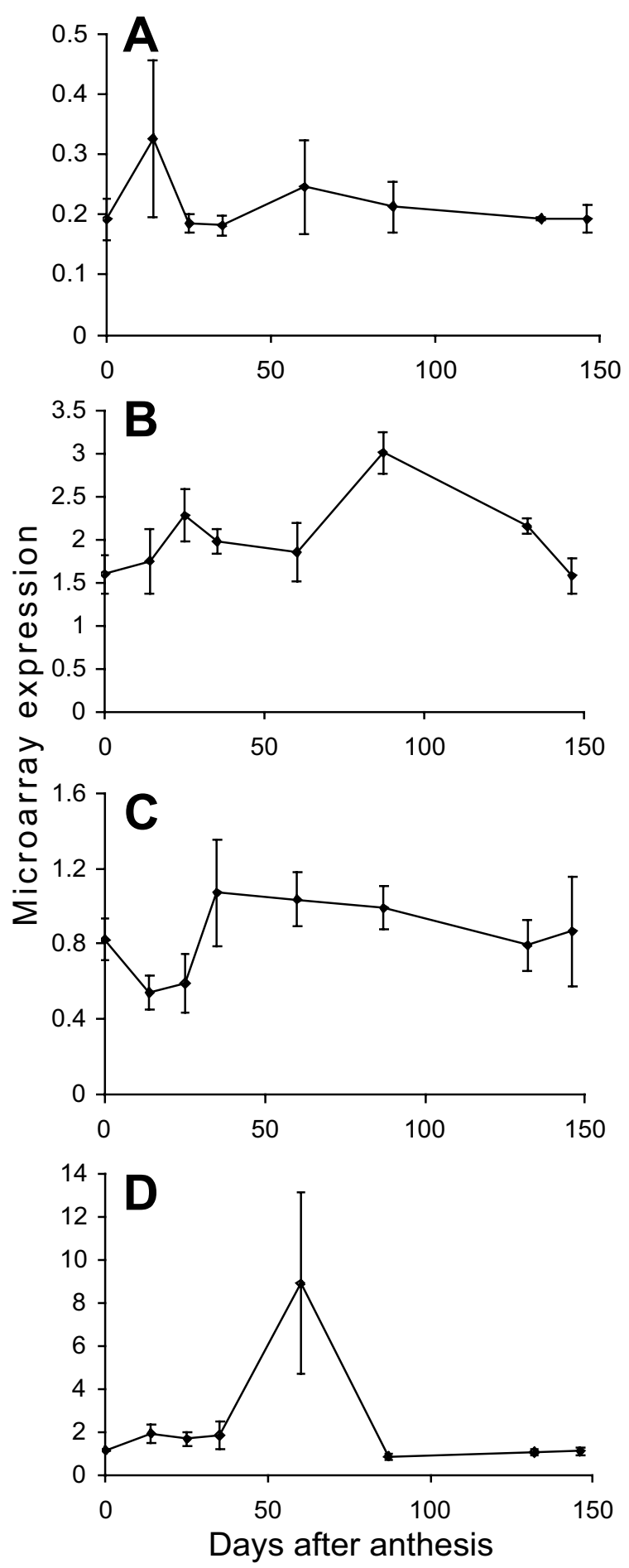

Figure 6

Expression pattern for candidate fruit development genes. Array expression patterns for apple homologues of Arabidopsis fruit development genes A, Spatula homologue EBI3254I, B, ettin/ARF3 homologue CN9I I459, C, Fruitfull/ AGL8 homologue EE663894, D, Yabby homologue $\mathrm{EB}|247| 2$ 
Table 5: Comparison of tomato and apple fruit development genes

\begin{tabular}{|c|c|c|c|c|}
\hline SGN-U ID (build 200607) ${ }^{\mathrm{a}}$ & TOMI SGN-M ID b & Apple Genbank acc. & Putative Annotationc & e valued \\
\hline \multicolumn{5}{|c|}{ Early fruit development cluster } \\
\hline SGN-U3।308| & $1-1-1.4 .4 .1$ & CN949202 & Tubulin & $4.00 \mathrm{E}-\mathrm{II}$ \\
\hline SGN-U334957 & $1-1-1.4 .2 .16$ & $\underline{E G 631180}$ & dimethyllallyl pyrophosphate isomerase & $2.00 \mathrm{E}-70$ \\
\hline SGN-U3।3439 & $|-|-|.2 .10 .2|$ & CN929316 & Catalase isozyme & $5.00 \mathrm{E}-67$ \\
\hline SGN-U3I24II & $|-|-3.1 .20 .8$ & CN929316 & Catalase isozyme & $1.00 \mathrm{E}-39$ \\
\hline SGN-U3|4745 & $|-|-6.2 .2 .12$ & $\underline{E B \mid 29157}$ & Histone $\mathrm{H} 2 \mathrm{~B}$ family & $5.00 \mathrm{E}-64$ \\
\hline SGN-U3I5396 & I-I-I.I.2.14 & $\mathrm{CN} 897140$ & Histone $\mathrm{H} 2 \mathrm{~B}$ family & I.00E-52 \\
\hline SGN-U320099 & $|-|-2.2 .8 .13$ & EBI34184 & homeodomain leucine zipper protein & $5.00 \mathrm{E}-50$ \\
\hline SGN-U3I2336 & $1-1-3.2 .14 .10$ & CN900880 & Chlorophyll a/b binding protein CP24 & $8.00 \mathrm{E}-45$ \\
\hline SGN-U3I6933 & $1-1-2.2 .10 .18$ & CN938965 & SLTI protein & I.00E-42 \\
\hline SGN-U3। 2305 & $1-1-4.1 .9 .2$ & EBII5858 & Tubulin & $5.00 \mathrm{E}-42$ \\
\hline SGN-U3।2306 & I-I-I.I.I7.|2 & CN898685 & Tubulin & $3.00 \mathrm{E}-37$ \\
\hline SGN-U3I 2504 & $|-|-4.2 .1 .2 \mid$ & CN929029 & Glycolate oxidase & $5.00 \mathrm{E}-33$ \\
\hline SGN-U3। 2724 & $1-1-3.2 .1 .14$ & CN929029 & Glycolate oxidase & $9.00 \mathrm{E}-22$ \\
\hline SGN-U3|353| & $I-I-5.3 .20 .16$ & $\underline{E B \mid 40736}$ & multi-copper oxidase type I family protein & $5.00 \mathrm{E}-33$ \\
\hline SGN-U3।4489 & $1-1-5.4 .1 .13$ & $\underline{E B} 128513$ & $\beta$-glucosidase & $5.00 \mathrm{E}-30$ \\
\hline SGN-U3।3179 & I-I-3.3.12.5 & $\underline{E B}|497| 4$ & Photosystem I reaction center subunit $\mathrm{N}$ & $3.00 \mathrm{E}-29$ \\
\hline SGN-U3। 3648 & I-I-I.I.2.9 & $\underline{E B} 139544$ & multi-copper oxidase type I family protein & $2.00 \mathrm{E}-26$ \\
\hline SGN-U3 I 4548 & $1-1-1.1 .14 .13$ & $\overline{\mathrm{EB} \mid 28647}$ & Peptidyl-prolyl cis-trans isomerase A & $6.00 \mathrm{E}-25$ \\
\hline SGN-U3 I 2538 & $1-1-1.3 .12 .16$ & $\underline{E B \mid 30656}$ & $60 \mathrm{kDa}$ chaperonin 2 (groEL protein I) & $8.00 \mathrm{E}-23$ \\
\hline SGN-U3 I 2683 & $1-1-2.1 .6 .18$ & CN900931 & Calreticulin precursor & $9.00 \mathrm{E}-19$ \\
\hline SGN-U319738 & $|-|-1.2 .11 .21$ & CN865336 & zinc (C3HC4-type RING finger) family & $3.00 \mathrm{E}-18$ \\
\hline SGN-U3I4473 & I-I-8.2.16.2 & $\underline{E B I 76490}$ & MADS-box protein (AGL3) RIN & $3.00 \mathrm{E}-17$ \\
\hline SGN-U3I7999 & $|-|-4.3 .10 .2 \mid$ & CN945062 & PGR5 related & $8.00 \mathrm{E}-17$ \\
\hline SGN-U3। 8625 & $1-1-2.3 .5 .9$ & $\underline{E B} \mid 14733$ & kinase-activating protein & $3.00 \mathrm{E}-16$ \\
\hline SGN-U3 I 2874 & $1-1-1.3 .11 .19$ & CN90985I & HMG protein & $7.00 \mathrm{E}-16$ \\
\hline SGN-U3।3470 & $1-1-2.1 .19 .16$ & $\overline{\mathrm{CN} 940020}$ & Hypothetical protein & $2.00 \mathrm{E}-13$ \\
\hline SGN-U333609 & $1-1-3.1 .10 .16$ & $\underline{E B \mid 40812}$ & expansin (EXPI5) & $7.00 \mathrm{E}-12$ \\
\hline SGN-U313166 & $1-1-6.1 .9 .20$ & $\underline{E B}|3| 083$ & Hypothetical protein & $2.00 \mathrm{E}-\mathrm{II}$ \\
\hline SGN-U3।4384 & $|-|-5.4 .4 .||$ & $\underline{E B 132156}$ & Lipid transfer protein (LTPI) & $1.00 \mathrm{E}-10$ \\
\hline SGN-U3I4386 & I-I-5.I.I5.I2 & $\underline{E B} 132156$ & Lipid transfer protein (LTPI) & $3.00 \mathrm{E}-07$ \\
\hline SGN-U313194 & $|-|-2.3 .4 .2 \mid$ & $\underline{E B}|3| 105$ & Photosystem I reaction center subunit psaK & $3.00 \mathrm{E}-10$ \\
\hline SGN-U3।3424 & $1-1-1.3 .1 .15$ & CN948056 & seed storage/lipid transfer protein family & 4.00E-10 \\
\hline SGN-U3। 4489 & $1-1-5.4 .1 .13$ & $\underline{E B|4| 224}$ & $\beta$-glucosidase, protein & I.00E-09 \\
\hline SGN-U3I 2690 & $|-|-2.1 .2 .8$ & $\overline{\mathrm{EB}|4| 004}$ & Plastocyanin & 2.00E-09 \\
\hline SGN-U336943 & $1-1-8.2 .6 .16$ & CN911937 & hypothetical protein & 7.00E-09 \\
\hline SGN-U331028 & $|-|-5.3 .5 .7$ & CN913037 & Hypothetical protein & $2.00 \mathrm{E}-08$ \\
\hline SGN-U3। 7844 & I-I-8.4.6.17 & $\overline{\mathrm{EB} \mid 40002}$ & subtilase family protein & $3.00 \mathrm{E}-07$ \\
\hline SGN-U3I 2690 & I-I-2.1.2.8 & $\underline{E B} 127862$ & Glycolate oxidase $e^{e}$ & 4.00E-07 \\
\hline SGN-U3। 3570 & I-I-I.I.I2.3 & CN909757 & hypothetical proteinf & $4.00 \mathrm{E}-07$ \\
\hline SGN-U3। 6057 & $1-1-6.4 .13 .2$ & CN8824I3 & Aspartyl protease family protein & 8.00E-07 \\
\hline SGN-U33460I & I-I-8.4.10.14 & CN887|30 & Aldehyde dehydrogenase 2B4 & $2.00 \mathrm{E}-06$ \\
\hline SGN-U319033 & $1-1-3.2 .20 .7$ & EBI33081 & bZIP transcription factor & $2.00 \mathrm{E}-06$ \\
\hline SGN-U3 I47I3 & $I-I-I .2 .1 .20$ & CN918915 & aldo/keto reductase familyg & $2.00 \mathrm{E}-06$ \\
\hline SGN-U3|426I & I-I-7.4.10.14 & $\underline{E B|48| 86}$ & photosystem I subunit III precursor & $6.00 \mathrm{E}-06$ \\
\hline
\end{tabular}

Mid development cluster

\begin{tabular}{|c|c|c|c|c|}
\hline SGN-U3I 2527 & I-1-4.2.20.9 & $E B \mid 30137$ & S-adenosylmethionine synthetase & $8.00 \mathrm{E}-109$ \\
\hline SGN-U3 I 2579 & $1-1-4.4 .6 .16$ & $\underline{E B} \mid 30137$ & S-adenosylmethionine synthetase & $4.00 \mathrm{E}-70$ \\
\hline SGN-U3I3529 & $1-1-6.3 .1 .18$ & $\overline{\mathrm{EB} 130137}$ & S-adenosylmethionine synthetase & $6.00 \mathrm{E}-75$ \\
\hline SGN-U3।3179 & $|-|-3.3 .12 .5$ & $\underline{E B \mid 48119}$ & Photosystem I reaction centre subunit $\mathrm{N}$ & $4.00 \mathrm{E}-47$ \\
\hline SGN-U3। 2700 & $\mathrm{I}-1-2.4 .10 .20$ & EBII0724 & Aquaporin PIPI.I & $9.00 \mathrm{E}-46$ \\
\hline SGN-U3।3179 & $1-1-3.3 .12 .5$ & EBI38262 & Photosystem I reaction center subunit) & $2.00 \mathrm{E}-42$ \\
\hline SGN-U3। 3283 & $1-1-2.1 .14 .13$ & EBI09090 & Peptidyl-prolyl cis-trans isomerase & $1.00 \mathrm{E}-37$ \\
\hline SGN-U3|28|4 & $1-1-3.3 .9 .20$ & CN943669 & Plasma membrane intrinsic protein & $5.00 \mathrm{E}-35$ \\
\hline SGN-U3I6986 & $|-|-3.1 .2 .||$ & $\overline{E G 631337}$ & class II heat shock protein & $6.00 \mathrm{E}-33$ \\
\hline SGN-U3।3962 & $1-1-5.2 .4 .10$ & $\overline{\mathrm{EB} \mid 43575}$ & Hypersensitive induced response protein & $7.00 \mathrm{E}-28$ \\
\hline
\end{tabular}


Table 5: Comparison of tomato and apple fruit development genes (Continued)

\begin{tabular}{|c|c|c|c|c|}
\hline SGN-U3/2403 & $1-1-2.2 .19 .9$ & EE663740 & Heat shock $70 \mathrm{kDa}$ protein & $1.00 \mathrm{E}-18$ \\
\hline SGN-U3I3542 & I-I-3.4.I.6 & CN882970 & plasma membrane protein & $8.00 \mathrm{E}-18$ \\
\hline SGN-U3 I 2953 & $1-1-3.3 .3 .13$ & $\underline{E B} \mid 29432$ & $\alpha$-expansin precursor & $4.00 \mathrm{E}-17$ \\
\hline SGN-U333609 & $1-1-3.1 .10 .16$ & EBI29432 & $\alpha$-expansin precursor & $2.00 \mathrm{E}-06$ \\
\hline SGN-U3I 4790 & $I-1-6.3 .18 .20$ & CN913939 & quinone-oxidoreductase protein & $4.00 \mathrm{E}-\mathrm{I} 7$ \\
\hline SGN-U3 I 4793 & $1-1-2.3 .17 .10$ & CN913939 & quinone-oxidoreductase protein & $2.00 \mathrm{E}-10$ \\
\hline SGN-U3 I 2450 & $1-1-7.3 .19 .9$ & EE663684 & I7.6 kDa class I heat shock protein & $2.00 \mathrm{E}-12$ \\
\hline SGN-U3 I 5846 & $|-|-3.2 .|| .||$ & CN866618 & CBL-interacting protein kinase & $2.00 \mathrm{E}-1 \mathrm{I}$ \\
\hline SGN-U3 I 4303 & $1-1-4.4 .8 .10$ & $\underline{E B}|38| 24$ & Fatty aldehyde dehydrogenase & $2.00 \mathrm{E}-10$ \\
\hline SGN-U3 I 8440 & $|-|-8 .|| 5.2 \mid$. & CN875978 & Hypothetical protein & $4.00 \mathrm{E}-08$ \\
\hline
\end{tabular}

\section{Ripening cluster}

\begin{tabular}{|c|c|c|c|c|}
\hline SGN-U3। 2527 & I-1-4.2.20.9 & EBI37890 & S-adenosylmethionine synthetase I & $6.00 \mathrm{E}-88$ \\
\hline SGN-U3। 2579 & $1-1-4.4 .6 .16$ & EBI 37890 & S-adenosylmethionine synthetase I & $5.00 \mathrm{E}-42$ \\
\hline SGN-U3। 3529 & $1-1-6.3 .1 .18$ & $\overline{\mathrm{EB} \mid 37890}$ & S-adenosylmethionine synthetase I & $3.00 \mathrm{E}-86$ \\
\hline SGN-U3। 2306 & $|-|-|.| . \mid 7.12$ & CN943168 & Tubulin & $5.00 \mathrm{E}-54$ \\
\hline SGN-U3|43|4 & $|-|-5.2 .14 .12$ & CN907169 & Hypothetical protein & $4.00 \mathrm{E}-44$ \\
\hline SGN-U3। 5828 & $1-1-3.2 .1 .16$ & CN940740 & Cytochrome $\mathrm{C}$ oxidase subunit protein & $5.00 \mathrm{E}-4 \mathrm{I}$ \\
\hline SGN-U334905 & I-I-4.I.6.7 & EBI30234 & $\beta$-carotene hydroxylase & $2.00 \mathrm{E}-39$ \\
\hline SGN-U3I 2904 & $1-1-1.3 .13 .18$ & $\underline{\mathrm{EB} I 50480}$ & haloacid dehalogenase hydrolase family & $6.00 \mathrm{E}-38$ \\
\hline SGN-U3|4358 & $1-1-4.3 .1 .2$ & $\overline{\mathrm{CN} 915191}$ & Alcohol dehydrogenase & $5.00 \mathrm{E}-33$ \\
\hline SGN-U319942 & I-I-4.4.2.20 & CN874208 & Membrane-anchored ubiquitin-fold protein & $2.00 \mathrm{E}-24$ \\
\hline SGN-U3I 6057 & $1-1-6.4 .13 .2$ & CN879999 & aspartyl protease family protein & $3.00 \mathrm{E}-22$ \\
\hline SGN-U3I7374 & I-I-8.2.2.7 & CN946592 & Hypothetical protein & $3.00 \mathrm{E}-19$ \\
\hline SGN-U336I33 & I-I-I.4.10.I & EG631183 & $\alpha$-amylase & $5.00 \mathrm{E}-19$ \\
\hline SGN-U3I890| & $1-1-1.3 .6 .2$ & $\overline{\mathrm{CN} 876487}$ & Hypothetical protein & $2.00 \mathrm{E}-17$ \\
\hline SGN-U316698 & $1-1-3.2 .1 .19$ & CN868148 & Seed maturation protein & $5.00 \mathrm{E}-17$ \\
\hline SGN-U3I6057 & I-I-6.4.13.2 & CN894718 & aspartyl protease family protein & $9.00 \mathrm{E}-16$ \\
\hline SGN-U3। 3923 & I-I-4.2.19.5 & CN883582 & SNFI protein kinase regulatory gamma & $9.00 \mathrm{E}-16$ \\
\hline SGN-U314I0I & $1-1-2.4 .13 .5$ & CN941714 & Chaperone clpB & $7.00 \mathrm{E}-15$ \\
\hline SGN-U3I7462 & I-I-2.4.16.8 & $\overline{\mathrm{CN} 884487}$ & Dual specificity protein phosphatase 6 & $5.00 \mathrm{E}-13$ \\
\hline SGN-U3|35|4 & $|-|-4.2 .3 .20$ & $\underline{E B I 52301}$ & 14-3-3 protein GFI4 upsilon (GRF5) & $2.00 \mathrm{E}-12$ \\
\hline SGN-U3। 3747 & I-I-2.3.3.5 & EBI28426 & vacuolar processing enzyme-lb & $3.00 \mathrm{E}-12$ \\
\hline SGN-U3I6038 & $|-|-3.1 .9 .||$ & $\underline{E E 663883}$ & Expressed protein & $9.00 \mathrm{E}-12$ \\
\hline SGN-U3 I 4449 & I-I-8.1.4.18 & CN90274I & hypothetical or unknown protein & $2.00 \mathrm{E}-11$ \\
\hline SGN-U3। 4453 & $|-|-2.4 .16 . \mid$ & CN902741 & hypothetical or unknown protein & 4.00E-II \\
\hline SGN-U3I33I5 & $|-|-3.1 .9 .2 \mid$ & $\overline{E G 631213}$ & Putative chloroplast-targeted $\beta$-amylase & $1.00 \mathrm{E}-09$ \\
\hline SGN-U328474 & I-I-8.4.1.16 & CN911230 & $\mathrm{NHL}$ repeat-containing protein & 2.00E-09 \\
\hline SGN-U3 | 4887 & I-I-3.3.3.14 & $\underline{\mathrm{EB} I 44737}$ & Phytoene synthase & $3.00 \mathrm{E}-09$ \\
\hline SGN-U3। 3474 & $1-1-3.1 .12 .20$ & $\overline{\mathrm{CN} 898201}$ & short chain dehydrogenase/reductase family & $3.00 \mathrm{E}-08$ \\
\hline SGN-U3224II & $1-1-6.1 .18 .17$ & EBI37522 & Homocysteine S methyltransferase I & 2.00E-07 \\
\hline SGN-U3I5858 & $|-|-5.3 . \mid I .3$ & $\overline{\mathrm{CN} 895375}$ & Universal stress protein & $2.00 \mathrm{E}-07$ \\
\hline SGN-U3I567I & $1-1-1.2 .16 .10$ & CN929435 & Ethylene-responsive DEAD box RNA helicase & 3.00E-07 \\
\hline SGN-U3|27|4 & $|-|-2.3 .9 .4$ & $\underline{E G 631274}$ & Cytochrome P450 85AI (C6-oxidase) & 2.00E-07 \\
\hline SGN-U3I27I5 & $|-|-|.| . \mid 5.15$ & $\underline{E G 631274}$ & Cytochrome P450 85AI (C6-oxidase) & 3.00E-07 \\
\hline SGN-U3 I 3547 & I-I-2.4.5.5 & CN917878 & Plasma membrane ATPase I (Proton pump I) & $4.00 \mathrm{E}-07$ \\
\hline SGN-U3I 2870 & $|-|-4.2 .15 .8$ & EE663893 & Xyloglucan:xyloglucosyl transferase & $6.00 \mathrm{E}-07$ \\
\hline SGN-U3I6695 & $1-1-1.2 .8 .9$ & $\overline{\mathrm{EB} I 11007}$ & Mitogen-activated protein kinase 3 & $7.00 \mathrm{E}-07$ \\
\hline SGN-U320099 & $1-1-2.2 .8 .13$ & EBII642I & Homeobox leucine zipper protein ATHB-4 & $2.00 \mathrm{E}-06$ \\
\hline SGN-U3I25I6 & I-I-1.3.7.19 & $\overline{E G 631323}$ & N-benzoyltransferase protein & $4.00 \mathrm{E}-06$ \\
\hline SGN-U3। 2884 & I-I-8.3.6.6 & CN862135 & Hypothetical protein & $6.00 \mathrm{E}-06$ \\
\hline
\end{tabular}

Genes identified as changing during tomato fruit development were used to identify apple genes present on the array that were also changing during fruit development.

a Gene identifier for the tomato gene containing the sequence on the TOMI array, from [53]

b Micrarray feature identifier from Alba et al. [13].

c Annotation of both the apple and tomato genes, based on BLAST comparison of genes with public databases.

$\mathrm{d}$ e value for the MegaBLAST comparison between the tomato gene and the apple gene that contain the sequence on the array.

e Annotation for tomato gene is: Plastocyanin, chloroplast precursor.

$\mathrm{f}$ Annotation for tomato gene is: Histone $\mathrm{H} 4$.

$g$ Annotation for tomato gene is: protein transporter. 

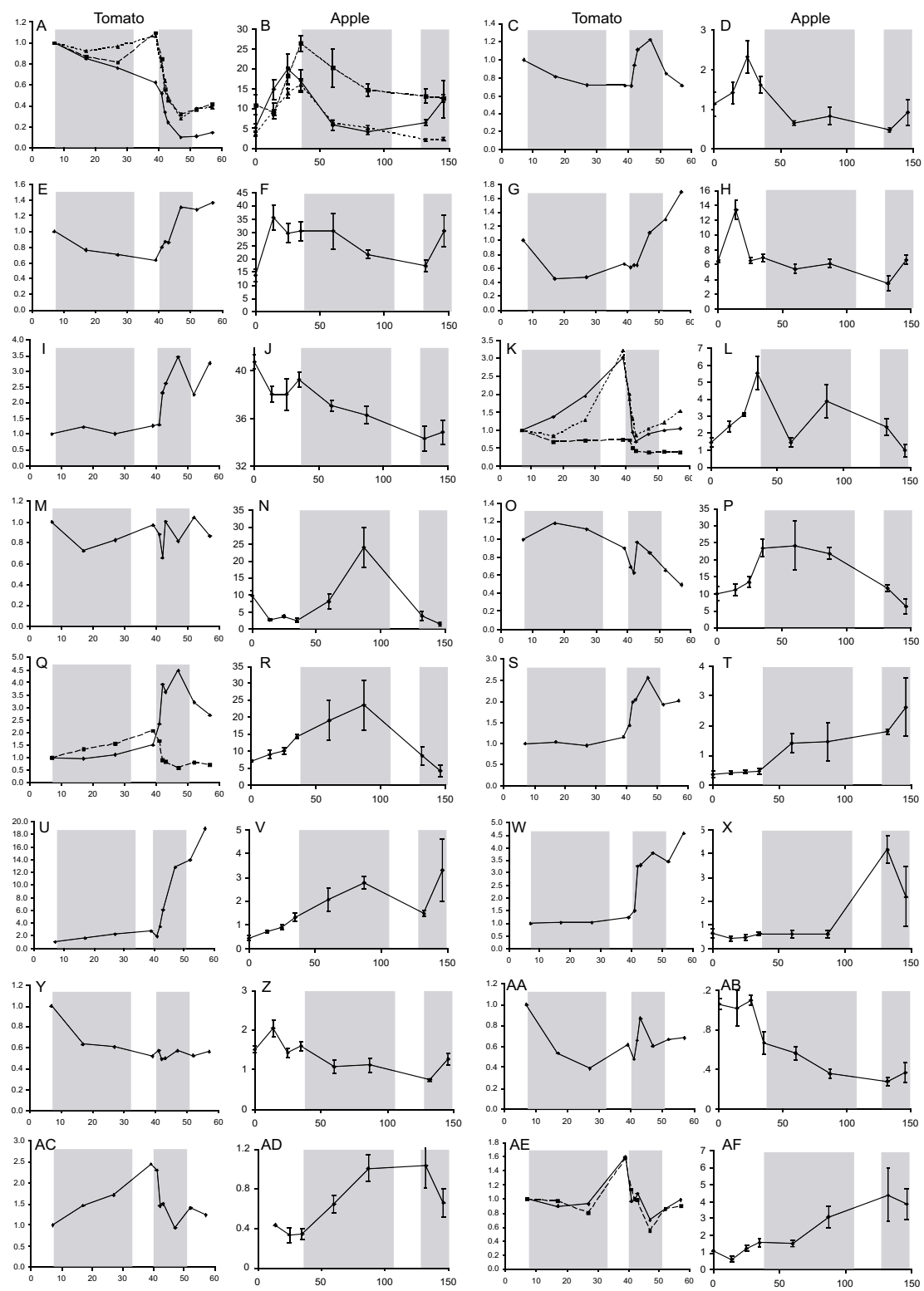

\section{Figure 7}

Comparison of apple and tomato expression. Expression of tomato and apple genes identified as changing during fruit development and similar by sequence comparison. Expression for tomato genes is plotted relative to 7 DAA and for apple as absolute expression; the $\mathrm{x}$ axes shows days after anthesis. Shaded areas in each graph correspond to the periods of cell expansion and ripening for both tomato and apple. A, C, E, G, I, K, M, O, Q, S, U, W, Y, AA, AC, AE tomato genes B, D, F, H, J, L, N, $P, R, T, V, X, Z, A B, A D, A F$ apple genes. $A$ and $B$, Tubulin homologues; $C$ and $D, I P P$ isomerase homologues; $E$ and $F$, Catalase homologues; $G$ and $H$, Histone 2B homologues; I and J, MADS box (RIN) homologues; $K$ and L, SAM synthase homologues; $M$ and N, PPlase homologues; $O$ and P, plasma membrane protein; $Q$, and $R, \alpha$-expansin homologues; $S$ and $T, \beta$-carotene hydroxylase homologues; $\mathrm{U}$ and $\mathrm{V}$, Alcohol dehydrogenase homologues; $\mathrm{W}$ and $\mathrm{X}$ Phytoene synthase homologues; $\mathrm{Y}$ to $\mathrm{AF}$ Unannotated proteins. A, solid line SGN-U3 I308I, dashed line SGN-U3 I2305, dotted line SGN-U3 I2306; B, solid line CN949202, dashed line EBII 5858, dotted line CN898685; C, SGN-U334957; D, EG63 I I80; E, SGN-U3 I3439; F, CN9293 I6; G, SGN-U3 I5396; H, CN897I 40; I SGN-U3 I4473; J, EBI76490; K, solid line SGN-U3 I 2527, dashed line SGN-U3 I2579, dotted line SGN-U3 I3529; L, EBI30 I37; M, SGN-U3 I3283; N, EB I09090; O, SGN-U3 I28I4; P, CN943669; Q, solid line SGNU3 I2953, dashed line SGN-U333609; R, EBI29432; S, SGN-U334905; T, EBI30234; U, SGN-U3I4358; V, CN9I5I9I; W, SGN-U3 I4887; X, EBI44737; Y, SGN-U3 I7999; Z, CN945062; AA, SGN-U3I3570; AB, CN909757; AC, SGN-U3I890I; AD, CN876487; AE, solid line SGN-U3I4449, dashed line SGN-U3I4453; AF, CN90274I. 
Table 6: Early apple fruit gene identified in 'Fuji' which change during 'Royal Gala' fruit development

\begin{tabular}{|c|c|c|c|}
\hline EFD genes from Lee et al. (2007) ${ }^{a}$ & expect value ${ }^{b}$ & Genbank acc for array oligo & Annotation \\
\hline \multicolumn{4}{|l|}{ EFD cluster } \\
\hline DW248931 & $1.00 \mathrm{E}-155$ & CN900880 & chlorophyll A-B binding protein (LHCl type I (CAB)) \\
\hline DW248987 & 0 & EBI27862 & Glycolate oxidase \\
\hline DW248917 & I.00E-177 & $\underline{E B} 127279$ & lipid protein \\
\hline DW248920 & 0 & $\underline{E B \mid 48186}$ & Photosystem I reaction center subunit III \\
\hline DW248842 & 0 & CN929029 & Glycolate oxidase \\
\hline DW248924 & 0 & EBII5972 & Ascorbate peroxidase \\
\hline DW248835 & 0 & EB|4049| & aquaporin TIPI.3 \\
\hline DW248922 & 0 & EBI497|4 & Photosystem I reaction center subunit $\mathrm{N}$ \\
\hline DW248839 & 0 & CN926591 & NADH dehydrogenase \\
\hline DW248976 & 0 & EBII 2578 & Trans-cinnamate 4-monooxygenase (Cytochrome P450 73) \\
\hline DW248868 & 0 & CN915536 & rapid alkalinization factor \\
\hline DW24888I & $1.00 \mathrm{E}-143$ & CN861574 & phytol kinase 2 \\
\hline DW248942 & 0 & CN861788 & Photosystem I reaction center subunit $V$ \\
\hline \multicolumn{4}{|l|}{ MD cluster } \\
\hline DW248803 & I.00E-87 & CN913162 & $\mathrm{CPI} 2$ protein \\
\hline DW248895 & $5.00 \mathrm{E}-95$ & EBI48680 & Oxygen-evolving enhancer protein \\
\hline DW248912 & $5.00 \mathrm{E}-163$ & CN870279 & I6.9 kDa class I heat shock protein \\
\hline DW248912 & $5.00 \mathrm{E}-163$ & $\underline{E G 63 \mid 337}$ & class I heat shock protein \\
\hline \multicolumn{4}{|c|}{ Not selected in Royal Gala fruit development } \\
\hline DW248927 & 0 & $\underline{E B} 127218$ & Polyphenol oxidase \\
\hline DW248967 & 0 & $\underline{E B I 27720}$ & Ferredoxin-thioredoxin reductase \\
\hline DW248839 & 0 & CN894409 & NADH dehydrogenase \\
\hline DW248924 & 0 & EBI38975 & Ascorbate peroxidase \\
\hline DW248940 & 0 & CN899704 & oligouridylate binding protein \\
\hline DW248833 & 0 & EBI 28528 & Hypothetical protein \\
\hline DW248979 & 0 & EBI 29884 & $\alpha$-expansin \\
\hline DW248918 & 0 & $\overline{\mathrm{CN} 944949}$ & Photosystem I reaction center subunit II \\
\hline DW24894I & 0 & CN8844II & chlorophyll A-B binding protein \\
\hline DW248844 & 0 & $\overline{\mathrm{EB} \mid 48603}$ & RuBisCO activase \\
\hline DW2489I4 & 0 & EB|48603 & RuBisCO activase \\
\hline DW248854 & $1.00 \mathrm{E}-129$ & $\underline{\underline{E B} \mid 48750}$ & Oxygen-evolving enhancer protein 2 \\
\hline DW248983 & 0 & $\underline{E B}|3| 2 \mid 8$ & fatty acid elongase 3-ketoacyl-CoA synthase I \\
\hline DW248994 & 0 & CN912337 & Glutamate-I-semialdehyde 2,I-aminomutase \\
\hline
\end{tabular}

Genes identified by [25] as up-regulated during EFD were used to identify apple genes present on the array.

a Genbank accession for those genes identified in Lee at al as up regulated in early fruit development with homologues present on our array.

$b$ expect value for the BLAST comparison between the Fuji gene and the apple gene which contains the array oligo.

both apple and tomato and are shown in Figure 7, with the cell expansion and ripening stages highlighted. A further five genes had some similarity of expression but 26 had little or no similarity of expression (data not shown).

For genes such as Tubulin (Figure 7A and 7B), SAM synthase (Figure $7 \mathrm{~K}$ and $7 \mathrm{~L}$ ) and an expansin homologue (Figure 7Q and 7R) more than one tomato sequence had homology to an apple gene and in the case of the tubulin genes to three apple genes. For the tubulin genes the patterns of expression mostly differed between apple and tomato but one of the tomato genes showed a steady decrease in expression during cell expansion similar to the apple genes. For the three tomato SAM synthase genes only one (SGN-U312579) had a pattern of expression similar to the apple gene suggesting this tomato gene may have a similar function in apple and tomato. For the two tomato expansin homologues with similarity to apple, SGN-U312953 increased in expression during ripening whereas SGN-U333609 and the apple expansin homologue both increased during cell expansion and declined in ripening, suggesting these genes may be orthologues and have a role during cell enlargement but not in fruit softening. Four genes without annotation were identified as having similar patterns of expression in apple and tomato fruit. Further bioinformatic analysis suggests that, 
Table 7: Fruit ripening genes which respond to ethylene

\begin{tabular}{|c|c|c|c|}
\hline Apple Genbank acc. & Putative Annotation ${ }^{\mathrm{a}}$ & Apple Genbank acc. & Putative Annotation ${ }^{a}$ \\
\hline \multicolumn{4}{|c|}{ Ripening sub-cluster $\mathbf{R}$ I } \\
\hline$\underline{E B} 118159$ & Short chain dehydrogenase/reductase (SDR) & $\underline{E B|4055|}$ & Hypothetical protein \\
\hline CN860849 & Ceramide kinase & CN906574 & Senescence associated protein \\
\hline CN870499 & Hypothetical protein & $\underline{E B} \mid 22632$ & Thaumatin protein \\
\hline$\underline{E B} \mid 27428$ & LEA family protein & CN911315 & DNA binding bromodomain protein \\
\hline CN895403 & Integral membrane family protein & $\underline{E B}|5| 4 \mid 4$ & Major latex protein (MLP) \\
\hline \multicolumn{2}{|c|}{ Ripening sub-cluster $\mathbf{R} 2$} & \multicolumn{2}{|c|}{ Ripening sub-cluster $\mathbf{R} 3$} \\
\hline$\underline{E B 106359}$ & Hypothetical protein & CN932083 & Chloroplast 50S ribosomal protein L22 \\
\hline CN862135 & Hypothetical protein & CN860052 & 5-oxoprolinase \\
\hline EBII4937 & $\beta$-glucosidase precursor & $\mathrm{CN} 860296$ & Hypothetical protein \\
\hline CN862240 & Transaldolase ToTAL2 & CN862389 & Stress-responsive protein \\
\hline$\underline{E B} \mid 16078$ & (S)-acetone-cyanohydrin lyase & CN864680 & (S)-2-hydroxy-acid oxidase \\
\hline EBII829| & Mannitol dehydrogenase & $\mathrm{CN} 851072$ & Calcineurin B-like protein \\
\hline CN849429 & Hypothetical protein & $\underline{E B}|2| 320$ & Ribosomal protein \\
\hline CN863631 & Sugar transporter & CN886293 & Isoflavone reductase \\
\hline$\underline{E B \mid 17418}$ & $(I-4)-\beta$-mannan endohydrolase & $\underline{\underline{E B} \mid 35086}$ & Carbonic anhydrase \\
\hline CN864737 & DNA polymerase III polC-type & $\underline{E B I 26988}$ & $\mathrm{C} 2 \mathrm{H} 2$-type zinc finger protein \\
\hline EBII5757 & Flavonol synthase & CN939170 & Glycerol-3-phosphate dehydrogenase \\
\hline$\underline{E B}|2| 772$ & Hypothetical protein & CN939718 & Sadl/unc-84 protein \\
\hline CN887217 & Hypothetical protein & CN890306 & Transaldolase protein \\
\hline CN890755 & CBL-interacting protein kinase & $\underline{E B} \mid 37446$ & Cytochrome P450 \\
\hline$\underline{E B}|355| 2$ & F-box family protein & CN894690 & NADH dehydrogenase \\
\hline CN893578 & C-4 methyl sterol oxidase & EBI37890 & S-adenosylmethionine synthetase \\
\hline $\mathrm{CN} 889902$ & Auxin/aluminum-responsive & $\underline{\mathrm{CN} 895673}$ & 2-oxoisovalerate dehydrogenase \\
\hline CN895410 & Hypothetical protein & $\underline{E B I 38408}$ & Hypothetical protein \\
\hline CN895502 & Vacuolar sorting receptor & $\underline{\mathrm{EB}} \mid 40312$ & Ribose-5-phosphate isomerase A \\
\hline EBI38209 & Xyloglucan endotransglycosylase & $\underline{E B \mid 4225 I}$ & Pectinacetylesterase \\
\hline$\underline{E B I 38429}$ & LEA family protein & CN941807 & DEAD box RNA helicase \\
\hline CN940062 & Harpin induced protein (HINI) & CN943134 & Hypothetical protein \\
\hline EBI39752 & Seed storage/lipid transfer protein & $\underline{E B} 129495$ & Stress-responsive protein \\
\hline EBI39896 & Auxin-responsive protein & CN943168 & Tubulin \\
\hline EBI28540 & Profilin & $\underline{E B} 129522$ & MYB transcription factor \\
\hline CN943110 & Syntaxin & CN945056 & Hypothetical protein \\
\hline EE663937 & Ethylene receptor (EIN4/ETR2) & CN883038 & Hypothetical protein \\
\hline$\underline{E B} \mid 40933$ & 6-phosphogluconolactonase & $\underline{E B I 50480}$ & Haloacid dehalogenase hydrolase \\
\hline$\underline{E B|4| 282}$ & Lipoxygenase & EE663647 & Hypothetical protein \\
\hline CN901620 & Hypothetical protein & $\underline{E G 631194}$ & S-adenosyl-L-methionine:carboxyl methyltransferase protein \\
\hline$\underline{E B I 4478 \mid}$ & Lipid transfer protein & CN876100 & SCARECROW gene regulator \\
\hline$\underline{E B \mid 48006}$ & Fimbrin protein (FIMI) & CN877052 & Hypothetical protein \\
\hline$\underline{E G 631181}$ & Thaumatin protein & $\underline{\mathrm{CN} 878203}$ & Copine I protein \\
\hline EG631195 & Transferase family protein & CN902180 & Amidase protein \\
\hline EG631213 & $\beta$-amylase & CN902277 & Hypothetical protein \\
\hline EBI57538 & Hypothetical protein & CN902592 & Heavy-metal associated domain-containing protein \\
\hline CN875931 & tat $\mathrm{D}$ deoxyribonuclease family & CN911536 & Hypothetical protein \\
\hline EG631252 & UDP-glucoronosyl/UDP-glucosyl transferase & $\underline{E B} \mid 54218$ & MADS-box protein \\
\hline EE663809 & Pyruvate kinase & CN914798 & Hypothetical protein \\
\hline CN912930 & Pentatricopeptide repeat protein & CN914935 & MATE efflux protein \\
\hline CN913545 & Hypothetical protein & CN914950 & 2OG-Fe(II) oxygenase family protein \\
\hline CN909301 & Hypothetical protein & CN917878 & $\mathrm{H}(+)$-transporting ATPase \\
\hline CN917441 & Dormancy/auxin associated & EE663837 & Hypothetical protein \\
\hline EBI52801 & Xyloglucan endotransglycosylase & CN916212 & AAA-type ATPase family protein \\
\hline CN915067 & Sugar transporter family protein & CN916137 & Phytase \\
\hline CN915323 & Hypothetical protein & EBI53327 & Isocitrate lyase \\
\hline EE663891 & Polygalacturonase & CN915191 & Alcohol dehydrogenase \\
\hline EG631317 & Cytochrome P450 & $\underline{E G 631278}$ & Cytochrome P450 \\
\hline
\end{tabular}

Apple genes for which expression changed in response to ethylene treatment of mature apple fruit from an ACC oxidase knockout plant [22] which also had significantly altered expression during fruit ripening in the fruit development array.

a Annotation of the apple genes, based on BLAST comparison of genes with public databases. 
CN945062 may be a PGR5 homologue involved in pho-

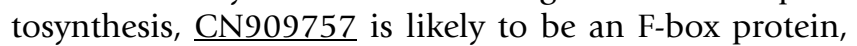
and $\mathrm{CN876487}$ which is expressed during cell expansion is similar to Sec5A and may be involved in exocytosis. However $\mathrm{CN} 902741$ still remains unannotated. The role of these genes in fruit development remains to be determined.

\section{Comparison of gene expression between apple cultivars}

A recent report has examined expression of apple genes early in fruit development using an array of 3484 cDNAs [25]. These authors identified 88 unique apple genes expressed more in whole young fruit (21 DAA) than in whole mature fruit (175 DAA) in the cultivar Fuji. Eightyfour homologues of these genes were identified in our EST database, 42 of these were represented on our microarray. Of these 42 genes, 17 were selected as changing significantly during fruit development, 13 in the EFD cluster and four in the MD cluster (Table 6).

Since the criteria used to select significantly changing genes was fairly stringent we plotted expression patterns for all the matches between our data and the selected early fruit development genes from Lee et al. [25] in order to identify any additional genes with similar patterns of expression (data not shown). Eighteen genes identified by Lee et al. [25] as being up-regulated were not confirmed in our microarray, however, an additional 13 genes were identified with high expression early in Royal Gala fruit development, and low expression in ripening (Table 6).

\section{Identification of ethylene responsive fruit development genes}

The hormone ethylene plays a major role in fruit ripening in many fruit, including apple, leading to the respiratory burst and final fruit softening [20,21,34,35]. Recent work has used a transgenic apple tree (expressing an antisense copy of the ACC oxidase gene) which produces no detectable ethylene to examine gene expression changes and production of volatile compounds associated with apple aroma [22]. Fruit from this tree mature, but do not ripen or soften, unless treated with exogenous ethylene. Schaffer et al. [22] used the apple oligonucleotide array described here to identify 944 apple cortex and skin genes that respond to ethylene. Because the ripe fruit samples in the fruit development experiment consisted of cortex tissue only we identified only those genes that change by at least 2 -fold in cortex (after excluding 25 genes with very low expression), giving a list of 456 genes that respond strongly to ethylene in fruit cortex. Of these 456 ethyleneresponsive genes, 106 also changed significantly during the ripening phase of normal fruit development. These ethylene-responsive fruit-cortex ripening genes are shown in Table 7 and are grouped by ripening sub-cluster. The distribution of the genes was uneven between the three clusters with a greater percentage of the R2 cluster also identified as ethylene responsive (10 of 70 genes $(14.3 \%$ ) in R1, 48 of 195 genes (24.6\%) in R2 and 48 of 408 genes $(11.8 \%)$ in $\mathrm{R} 3)$. Included amongst these genes was one gene identified as a putative ethylene receptor, most similar to the ETR2/EIN4 receptors from Arabidopsis (apple EST166801, Genbank acc. EE663937). The apple microarray also contains oligonucleotide probes for four additional putative ethylene receptor genes. Expression of three of these genes was not significantly changed during the ethylene microarray experiment or during normal fruit ripening (apple EST152541, Genbank acc. CN898978, apple EST248756, Genbank acc. CN910963, apple EST244637, Genbank acc. CN902679). The fourth gene (apple EST166743, Genbank acc. EE663931, most similar to the ERS1/ETR1 receptors from Arabidopsis) was selected as induced by ethylene, and although it was not selected as significantly changing during fruit development, it does show some induction in normal fruit ripening.

\section{Discussion Confirmation of microarray expression patterns by $q R T$ - PCR}

At each of the steps used to produce microarray data, variability can be introduced leading to potential errors. We used qRTPCR of cDNA from the same samples of RNA used in the microarray experiment itself to estimate the overall accuracy of our data. Overall we found good correlation between qRT-PCR and microarray results with 75\% of microarray expression patterns reproducible by qRTPCR. However, $25 \%$ of expression patterns for which the qRT-PCR results did not match the microarray result. In some cases $(\sim 5 \%)$, this difference seems to be associated with genes where the genomic DNA reference sample gave very high intensity binding. It is possible that this high level of gDNA binding distorted the ratios observed or the gDNA binding may have interfered with cDNA binding for those genes. Another possible explanation for qRTPCR results disagreeing with microarray results is that the oligo on the microarray was able to hybridise to more than one allele of a gene in the sample, and qRT-PCR primer binding was more specific. Alternatively the microarray oligo may be hybridizing to more than one member of a gene family. These results would suggest that hybridization conditions on the microarray are not stringent enough, however during initial optimization of the methods any increase in stringency resulted in a large loss of signal intensity (data not shown). Furthermore, we have approximately 20 oligos on the array that were designed to EST sequences which when re-sequenced were shown to have a single base mismatch to the consensus sequence, these oligos do not bind labelled targets whereas perfect match oligos to the same targets do produce good signal 
(data not shown) suggesting hybridization stringencies are close to optimal.

\section{Different functional classes of genes are expressed at different times during fruit growth}

A comparison between the whole array and the selected 1955 genes identified differences in distribution of functional categories, suggests that the genes selected as changing significantly is a non-random selection from the whole array. The increases in "metabolism" and "energy" classes as compared with the whole array are not unreasonable given the large changes occurring in organ development and the accumulation of starch and sugar and later in ripening and production of flavour compounds. The remaining functional classes show only minor differences between the whole array and the selected 1955 and this may reflect some bias in the EST sequences [24]. Since the majority of libraries used in the original EST sequencing were from fruit or floral buds, it is reasonable to expect functional classification of the whole array to be similar to the classification for those genes regulated in fruit development.

When the functional classifications for the four major clusters are compared, some interesting changes in the proportions of genes in each category are observed, although interpretation of these changes must be made with caution since each cluster represents a different set of genes. The proportion of metabolic and energy gene functions is high in buds and declines during development and then increases in ripening fruit. This late increase may reflect an increase in secondary metabolite gene expression as flavour compounds are produced during ripening. An indication of this can been seen when the functional categories are examined in more detail. While the overall "metabolism" classifications are similar for FB and ripening clusters (21.5\% vs $20.9 \%$ ) the MIPS category 01.06 for lipid, fatty-acid and isoprenoid metabolism, which include the known flavour components such as terpenes, shifts from $2.6 \%$ in $\mathrm{FB}$ to $4.3 \%$ in the ripening cluster (data not shown).

A limitation of functional analysis is that it can only provide information about genes for which some function has been previously identified. While functional classification of genes is a useful approach to analysis of microarrays it is the combination of functional classification with other approaches (e.g. clustering) that allows information to be more easily identified in the data, for example identifying genes associated with cell division that are most highly expressed early in development.

\section{Cell cycle genes are regulated at the transcriptional level early in fruit development}

The development of apple fruit involves an early period of cell division that lasts for approximately 30 days after pollination $[17,18]$. Regulation of cell cycle genes is complex however it is possible that transcriptional regulation of some of the core cell cycle genes are involved in the control of cell division during fruit development. Control of the core plant cell cycle genes at the transcriptional level has been associated with regulation of the cell cycle in synchronised Arabidopsis and tobacco BY2 cell cultures [30,36-38]. Because of the nature of our samples, we would not be able to detect such cycle-dependent transcriptional regulation. However, at least one of the core cell cycle genes has been shown to be regulated developmentally in plants; CDKB1;1 has been associated with control of cell division in Arabidopsis leaf development, and expression of CDKB1;1 declines as Arabidopsis leaves get older $[39,40]$. Alteration of CDKB1;1 activity in leaves by expression of a modified form of CDKB $1 ; 1$ changes cell size and endoreduplication. Two putative CDKB homologues in the apple fruit development microarray changed significantly, both of these apple genes decline in expression at the time that apple cell division stops suggesting a role for these genes in the regulation of this process. The third core cell cycle gene that changed significantly during fruit development is a CKS1 homologue. CKS1 has been shown to associate with CDKB proteins and has been proposed to act as a docking protein for regulators of CDK activity [41] and also has been shown to associate with the SCF complex involved in degradation of kinase inhibitor proteins (KIPs in animals, KRPs in plants, [41,42]). The expression of these three cell cycle associated genes at the time when apple fruit are undergoing cell division suggests they are important developmental regulators in apple. Altering expression of these genes would allow elucidation of their function and perhaps lead to fruit with altered cell numbers leading to changes in fruit texture and size.

The G1 to S transition is an important control point in the plant cell cycle and the CycD3;1 gene has been shown to be limiting for this transition in Arabidopsis [43]. No orthologue for this gene has been identified in apple although three homologous genes are represented on the array. None of these homologues varied significantly during development but one (EB132575) declined approximately 2 -fold late in apple fruit development.

Endoreduplication has been associated with increases in cell size in many plants [44]. Studies in Arabidopsis suggest that inhibition of mitotic CDK complexes by the kinase inhibitors KRP1 [45] and KRP2 [46] and the kinase Wee1 [47] can lead to increased endoreduplication. Interestingly, a recent report suggests there is no endoredupli- 
cation in mature apple fruit [48]. Perhaps not surprisingly then, apple homologues of these genes were not selected as having changed significantly during fruit development, however the apple Weel homologue does show some increase in expression immediately after cell division ceases. The role of these genes in regulation of endoreduplication in apple, if any, is not clear but it may be possible to induce endoreduplication in apples by altering expression of these genes.

\section{Starch metabolism is regulated at the transcriptional level in fruit}

Although the biochemical activities of many starch enzymes have been defined, it is difficult to assign the roles of different enzyme pathways in the regulation of starch levels in fruit. Matching the gene expression profiles produced in this study to known changes in starch content throughout apple development is one approach, implicating certain pathways in these processes. While we did not observe coordinated expression of complete pathways, there was co-expression of several genes in one pathway. For example, the expression profiles of sucrose phosphatase (EB156512) and a sucrose-phosphate synthase (EB123469) mirrored the reduction in apple starch content during both early fruit development and during ripening [19], suggesting that these enzymes may be components of the starch degradation pathway in fruit development. However, it is also possible that distinct pathways are responsible for these early and late starch degradation events. The high transcript levels of $\beta$-amylase (EB114557) and $\alpha$-glucosidase (EE663791) early in development but not during ripening are evidence of a starch degradation pathway that may be specific to early development and not active in late development. These results suggest that distinct starch metabolic pathways are important and are regulated at the transcriptional level in apple fruit development.

One observation made during the analysis of the starch metabolism pathways was that for any given step there were usually several candidate genes for a particular enzyme. For example there are two plastidic starch synthases in the Arabidopsis databases. Both have homologues in the apple EST database, and one has homology to two apple genes. Expression of only one of these candidate starch synthase genes in apple fruit (represented by EB121923, Figure 5) peaked at 87 DAA, just prior to the peak in fruit starch content at 100 DAA [19]. This correlation of expression data with the pattern of starch accumulation during development suggests that this particular starch synthase gene is involved in regulation of starch levels during fruit development. These results show that microarrays can be used to correlate transcript levels with physiological and biochemical observations to identify which member of a gene family, or even perhaps which allele, is likely to be involved in the process of interest.

The expression profiles of nine starch enzymes (Figure 5) showed that developmental regulation of the transcription of these genes corresponds to observed changes in starch levels throughout apple development. In a similar study, Smith et al. [49] used Affymetrix microarrays to observe echanges in the expression of starch enzymes over a diurnal cycle in Arabidopsis leaves. In leaves, starch is synthesised in the light and degraded in the dark. These authors observed distinct changes in the transcript levels of enzymes such as starch synthase and $\beta$-amylase. It is interesting that there is evidence of transcriptional regulation of starch in both Arabidopsis leaves where light- and sugar-regulated changes in starch occur over a 24 -hr period, and in apple fruit where developmental regulation of starch takes place over a 146-day period. This transcriptional regulation of starch in both source and sink tissues may be required to coordinate the partitioning of carbohydrates throughout a plant.

\section{Comparison of microarray experiments examining fruit development}

Comparison of microarray experiments from different species targeted to the same developmental process offers the opportunity to compare gene expression patterns for a large number of genes. The attraction of such a comparison is that it may identify processes common to different fruit and hence important in the fundamental processes occurring in all fruit. For some published studies however, the size of the datasets and/or differences in samples studied make comparisons of limited value $[11,15,25]$. For example, specific searches of the tomato microarray results given by Lemaire-Chamley et al. [11] for genes expressed in both apple (this work) and tomato [13] early in fruit development did not identify similar genes, probably because these genes were not included in the Lemaire-Chamley array of 1393 tomato cDNAs e.g. IPP isomerase homologues (SGN-U334957 and EG631180), catalase homologues (SGN-U313439 and CN929316) and Histone 2B homologues (SGN-U315396 and CN897140). Where the apple microarray identified a CDKB2 gene as up-regulated early in fruit development (dividing cells), a comparison of tomato locular (expanding cells) and tomato pericarp (dividing cells) identified a CDKB2;2 homologue as up-regulated in locular tissue [11].

A microarray experiment using apple (3484 cDNAs, 'Fuji') compared 21 DAA with fully ripe fruit [25]. Comparing our data with that of Lee et al. [25] allows identification of regulated genes that may be otherwise excluded as not significantly changing in one of the two experiments. One such gene is EB129884 an $\alpha$-expansin homologue, identi- 
fied as highly expressed in 21 DAA fruit in the Fuji microarray, was excluded from the Royal Gala microarray by ANOVA analysis because two samples (132 and 146 DAA) had no detectable expression. In the Royal Gala microarray this $\alpha$-expansin had strongest expression at 14 DAA and maintains expression through to 87 DAA and then has no detectable expression, making it a good candidate for an expansin involved in the formation and expansion of the fruit cells. Without the comparative analysis with the data from the Fuji microarray this gene would not have been identified.

Using a microarray containing 12899 ESTs representing 8500 tomato genes Alba et al. [13] studied gene expression through tomato fruit development, focusing predominantly on ripening. It was perhaps surprising to find only 102 genes in common between the tomato fruit development microarray and the apple data presented here. The differences in experimental design may be one reason for this small overlap, with the tomato microarray having more sampling around ripening and the apple microarray more sampling of the floral bud and early fruit development. It may also be an indicator of the differences between apple and tomato fruit development.

When expression patterns for the similar apple and tomato genes were compared, only 16 out of 46 genes studied had similar patterns of expression in both apple and tomato. Since approximately $75 \%$ of apple microarray expression patterns are reproducible in qRT-PCR, and presumably the same is true for the tomato microarray, for each pair of genes there is only an approximately 56\% chance that both patterns are reproducible. Thus at best we would expect only 26 pairs to have the same pattern of expression. In addition, since the sequence similarity threshold used was fairly low it is also likely that some of the pairs of genes examined are not orthologous genes. Nevertheless it is likely that identifying only 16 pairs of genes with similar expression patterns in both apple and tomato is an underestimate of the actual similarity between the fruit. Where patterns of expression do have similarity between apple and tomato it is probable that the microarray pattern of expression represents the actual pattern of expression for those genes, since the expression pattern has effectively been confirmed in another species. It is probable that when more complete whole genome arrays are used and when more closely matched sampling is carried out, many more genes with similar expression will be identified. As further microarray experiments are performed in other fruiting species the inclusion of samples at standardized developmental stages will allow better comparison of datasets and more common fundamental processes to be identified.
Of the 16 pairs of tomato and apple genes identified, seven show up-regulation in ripening and four showed down-regulation. This almost certainly reflects the emphasis on ripening samples in the tomato microarray. Homologues of $\beta$-carotene hydroxylase, alcohol dehydrogenase and phytoene synthase are all up-regulated during ripening in both apple and tomato, suggesting these enzymes play significant roles in formation of the colour and flavour compounds associated with ripening fruit. However, carotenoids are not typically high in apple fruit flesh [50] suggesting either that production of carotenoids in apples is blocked at another step in the biosynthetic pathway or that the products of these enzymes are further processed into forms that have not yet been measured in apples. While homologues of IPP isomerase, catalase, Histone $2 \mathrm{~B}$ and the RIN MADS-box gene are all up-regulated in ripening in both apple and tomato they were all also selected in the apple microarray as up-regulated early in fruit development, although for the MADS-box gene the up-regulation may be more associated with high expression in floral buds. The role of this early expression for these genes is uncertain but it would be interesting to see if they were also highly expressed early in tomato fruit development. One integral plasma membrane protein homologue and one expansin homologue showed similar patterns of expression in both apple and tomato and were selected in the mid development cluster in the apple microarray. This result suggests these two genes play important roles in cell expansion during fruit development. We also identified genes without annotation that have similar patterns of expression in both apple and tomato fruit. Such comparisons are valuable in order to find genes for which the function is conserved for a particular process that may not be identified by other methods. Further work will allow us to determine whether these genes indeed play an important role in fruit development.

\section{Intersections between different apple microarray experiments}

A comparison between two apple experiments using the same microarray was useful to identify genes involved in both fruit ripening and the ethylene response. The combination of the two datasets provides more information than each experiment on its own. The importance of ethylene in apple fruit ripening is demonstrated by the lack of ripening in ACC oxidase knockout fruit [22]. When we compared datasets from the ethylene induction and the fruit development microarray, 106 of the ethylene induced genes (in cortex) were found in the ripening cluster (668 genes) of the developmental microarray. The observation that 350 of the ethylene induced genes were not identified as having altered expression during the endogenous ripening process implies that these genes do not have roles in normal fruit ripening, or that the induction of these genes is below the level of significance used 
to select genes in this work. These results suggest that while ethylene is a major regulator of gene expression in fruit ripening, a large portion of fruit ripening occurs in the absence of ethylene. Using this comparative approach it is possible to identify fruit ripening events that are both ethylene dependent and independent.

\section{Conclusion}

The data presented here provide a picture of the molecular events occurring throughout the development of the apple fruit and provide a resource for future study of fruit development. We have identified genes that are likely to be important in some of the major processes. Comparison of the apple data with other fruiting plants identified 16 genes that may play fundamental roles in fruit development. Comparisons between experiments in apple allows differentiation between ethylene dependent and independent ripening. Future work will determine the specific function of these genes. Functional analysis of CDKB and CKS expression in fruit tissue early in development may reveal the mechanisms that control the growth of the cortex tissue to surround the core. Manipulation of expression of these genes may alter cell size and number in fruit, perhaps affecting fruit shape, size and texture. These data allow us to begin to develop an understanding of the molecular events that lead to the division and expansion of tissues surrounding a developing seed to form a fruit.

\section{Methods}

\section{Growth and maintenance of trees and sampling}

Apple (Malus $\times$ domestica Borkh. also known as M. pumila) trees from 'Royal Gala' were grown on M9 rootstocks and managed according to standard orchard practices (except that no chemical fruit thinning was allowed to take place).

For the 0 DAA sample, buds were stripped of petal and petiole but otherwise not further dissected. For samples taken at 14, 25, 35 and 60 DAA, whole fruit were sampled with only the petiole removed. For each sample at least 10 individual whole fruit were pooled. For samples taken at 87, 132 and 146 DAA cortex tissue only was dissected from at least 10 fruit and pooled. All samples were frozen in liquid nitrogen at time of harvest and then stored at -70 ${ }^{\circ} \mathrm{C}$.

\section{RNA extraction}

Total RNA was extracted from $6 \mathrm{~g}$ of each tissue ground under liquid $\mathrm{N}_{2}$ conditions using a modified method of Chang et al. [51]. The protocol was amended with a $1 \mathrm{~min}$ polytron step after addition of the extraction buffer, the aqueous phase after the first chloroform extraction was filtered through autoclaved Mira cloth, and the total concentration of LiCl was $2 \mathrm{M}$. Isolated RNA was column purified (using RNAeasy Mini Kit, Qiagen, Hilden, Germany) and the quality and purity was checked using an Agilent 2100
Bioanalyser (Agilent, Palo Alto, CA). RNA was ethanol precipitated and resuspended to $12.5 \mu \mathrm{g} / \mu \mathrm{L}$.

\section{Array design}

Apple ESTs were grouped into non-redundant sequences and unigenes as described in Newcomb et al. [24]. For each EST, oligonucleotides were designed using an inhouse algorithm, with a $\mathrm{Tm}$ of $74^{\circ} \mathrm{C} \pm 2{ }^{\circ} \mathrm{C}$ and length between 45 and 55 bases. Oligos with inverted or direct repeats and runs of more than 5 identical nucleotides were eliminated. A single oligo was selected for each unigene from the EST closest to the 3 ' end of the unigene and where more than one possible oligo was available for an EST, the 3' most oligo selected. As a final selection criterion unigenes were compared (using BLAST) with the database of apple unigenes and to the Arabidopsis protein database. For apple unigenes with high sequence similarity to other apple unigenes or where two apple unigenes had high sequence similarity to the same Arabidopsis protein only a single representative apple unigene was selected for oligo design. Using these criteria 15726 apple oligos were designed corresponding to 15145 apple unigenes (Table 1). Comparison of the apple unigenes with Arabidopsis and other plants suggests that the array contains approximately 13000 different genes. Oligos were synthesized commercially (5000 by Operon and 10726 by Illumina). Oligos were resuspended in $150 \mathrm{mM}$ NaPO4 pH 8.5 containing $0.00001 \%$ SDS to a final concentration of $20 \mu \mathrm{M}$ and printed on epoxy array slides (Quantifoil) using a MicroGrid TAS arrayer using 16 microspot 2500 pins for a total of 32 blocks. Since oligos were selected and synthesized in random order, no additional randomization of the array was necessary.

In addition to the sample oligos, each block contains four types of control oligos (Table 8). Group 1, apple oligos designed from: the 3', middle and 5' ends of an apple actin unigene (MdAC1-3, EST3793, Genbank acc. CN935584), an apple ubiquitin unigene (MdAC4-6, EST14223, Genbank acc. EB109811) and an apple elongation factor-1- $\alpha$ gene (Md AC7-9, EST704, Genbank acc. CN934151); oligos from apple rubsico small subunit (MdAC10, EST 59854, CN862467); an apple homeobox unigene, 5' end (MdAC11, EST87558, Genbank acc. CN870331), 3' end (MdAC12 EST29626, Genbank acc. EB111272) and conserved domain (MdAC13, EST29626, Genbank acc. EB111272); an apple MADS-box gene, 3' untranslated region (MdAC14, EST58802, Genbank acc. EB175510), 3' coding region (MdAC15, EST64768, Genbank acc. EB116541) and MADS domain (MdAC16, EST15992, Genbank acc. EB114519).

Group 2, control oligos associated with transgenic plants: Bacillus thuringiensis cry1Ac (BtAC17, Genbank acc. U89872); Streptomyces hygroscopicus phosphinothrycin 
Table 8: Control oligos

\begin{tabular}{|c|c|c|c|c|}
\hline Control name & Apple EST & Genbank Acc. & TAIR acc. & \\
\hline $\mathrm{MdACl}$ & 1412 & EBI06245 & & CGAACCAACACCAAAGGCCCTCAAGGCGGGCAGCATCACTACCAT \\
\hline MdAC2 & 1412 & $\overline{\mathrm{EB} 106245}$ & & GCTCTTCCACATGCCATCTTGAGGCTTGACCTTGCAGGTCGTGAT \\
\hline MdAC3 & 1412 & $\overline{\mathrm{EB} 106245}$ & & TACTTAAAATGTCTGGATTCTATGAGTTTGTAGGTTTGCCGCTGG \\
\hline MdAC4 & 14223 & EBI098II & & СTTCAATCTGAAAAATCTTCCTTCAAATTCTCTTTCCAAGCTTCTTCAGCC \\
\hline MdAC5 & 14223 & $\overline{E B 109811}$ & & TGAGGTGGAGAGCTCCGACACCATAGACAACGTGAAGGCCAAGATTCAAG \\
\hline MdAC6 & 14223 & $\overline{E B 109811}$ & & AATGGTACTGTTTTTGCCTCCTAAGATGAGGCATCTGGGCAAGTTTGTG \\
\hline MdAC7 & 704 & CN934I5I & & CAACATCGTGGTCATTGGCCATGTCGACTCCGGCAAGTCGACCAC \\
\hline MdAC8 & 704 & $\overline{\mathrm{CN} 934151}$ & & TGTTGAGACTGGTATCGTCAAGCCTGGTATGGTTGTGACTTTTGG \\
\hline MdAC9 & 704 & $\overline{\mathrm{CN} 934151}$ & & GGTGGTGACCCATCAAGTTTATGTTGTGTCGATTCCGCCTTCTGA \\
\hline $\mathrm{MdACIO}$ & 59854 & $\overline{C N 862467}$ & & GTGTTATGTATGCATAAGGAAGGTTATGGTTTATGCTGCTCCCTG \\
\hline MdACII & 8626 & CN923132 & & GCCATAAGCTTTAAGCTCTTCTCTCTGATTTCTCACAATTCAACTCGC \\
\hline $\mathrm{MdACI} 2$ & 29626 & $\overline{\mathrm{EB} I I I 272}$ & & ACGAGCCTTGCACCAACCTTAATTTGAAAAGAAGTAATGCAAGTG \\
\hline MdACI3 & 29626 & $\overline{E B I I I 272}$ & & AAGACGATAAACAACTGGTTCATCAATCAGCGGAAGAGGAACTGG \\
\hline $\mathrm{MdACl} 4$ & 58802 & $\underline{E B I 75510}$ & & CCTGGGTGGATGCTTTGACTTTGTTTGTGCCTAATAATAATACCC \\
\hline MdACI5 & 64768 & EBII654I & & GACTCTGGAACCATTATATGAATGCCATCTCGGATGCTTTGCTGC \\
\hline $\mathrm{MdACl} 6$ & 15992 & $\overline{\mathrm{EB} I \mid 4519}$ & & ACGAATCGAGAACACGATAAGCAGGCAAGTGACATTCTCAAAGAG \\
\hline $\mathrm{BtACI7}$ & & U89872 & & TTCCAATTCACTTCCCATCGACATCTACCAGATATCGAGTTCGTG \\
\hline ShACI8 & & $\times 17220$ & & CACCATCGTCAACCACTACATCGAGACAAGCACGGTCAACTTCCG \\
\hline AvACI9 & & $\mathrm{AF} 078810$ & & GCCCTGTCCTTTTACCAGACAACCATTACCTGTCCACACAATCTG \\
\hline $\mathrm{HsAC20}$ & & $\overline{N M 000518}$ & & GTGTGGCTAATGCCCTGGCCCACAAGTATCACTAAGCTCGCTTTC \\
\hline EcAC2I & & $\mathrm{A} 00196$ & & TAACAAGAAAGGGATCTTCACTCGCGACCGCAAACCGAAGTCGGC \\
\hline $\mathrm{EcAC22}$ & & $\overline{\mathrm{K} 01193}$ & & GTCTGGACCGATGGCTGTGTAGAAGTACTCGCCGATAGTGGAAAC \\
\hline $\mathrm{PpAC23}$ & & $\times 65316$ & & AGAGAGATCCTCATAAAGGCCAAGAAGGGCGGAAAGTCCAAATTG \\
\hline EcAC24 & & $\overline{\mathrm{V} 00618}$ & & TCGCAGCGCATCGCCTTCTATCGCCTTCTTGACGAGTTCTTCTGA \\
\hline $\mathrm{HsAC25}$ & & $\overline{\mathrm{AFI} 26021}$ & & CAGTGTTGTTCССTCССТCAAGGCTGGGAGGAGATAAACACCAAC \\
\hline $\mathrm{HsAC26}$ & & $\mathrm{X} 13988$ & & AAGAGTGAGCCAGCCCTTCTGGAGCAGGAGCAGGACAGAAGATAT \\
\hline $\mathrm{HsAC27}$ & & $\overline{M 21812}$ & & CACGCAGTGTGACCGCTTCTCCCAGGAGGAGATCAAGAACATGTG \\
\hline $\mathrm{HsAC28}$ & & $\times 07868$ & & TCAGCTCCTTTAACGCTAATATTTCCGGCAAAATCCCATGCTTGG \\
\hline $\mathrm{HsAC29}$ & & AK001779 & & GTGCCGGACTTACCTTTCATTGAACATGCTGCCATAACTTAGATT \\
\hline $\mathrm{HsAC30}$ & & $\overline{\mathrm{AFI} 61469}$ & & ATGCTTAAGATTCAACTGGGAGCATACCAGGGATGCTCTCTAACG \\
\hline HsAC3I & & NM 004048 & & TGGCAACTTAGAGGTGGGGAGCAGAGAATTCTCTTATCCAACATC \\
\hline $\mathrm{HsAC} 32$ & & NM 000291 & & GCTCATCTTCACTGCACCCTGGATTTGGATACATTCTTCAAGATC \\
\hline $\mathrm{HsAC} 33$ & & $\underline{L 11329}$ & & GTGTCATGTTGCGTGTGTCTGTCTGTGAGCCTTTCACACCTGTGC \\
\hline $\mathrm{HsAC} 34$ & & $\underline{\mathrm{UI} I 861}$ & & GAGTTGGAGCACGGTCTCTATGGGGAAGCGTTCGCTGTCTATCAG \\
\hline Auncl & & & At $\lg \mid 4400$ & GCTAACTCCTGATGGAGAGCTTTCGAAAATCAGTTGAATCAACCTCTGTT \\
\hline Aunc2 & & & Atlg16210 & GTCGATTTCATCATCATGTCCACCGATGTGCATTTGCAATTTGAAACGCAT \\
\hline Aunc3 & & & Atlg43900 & CCGGCTCAGAGTAAGGACTTGGATTCCTACCTTATTGGTAGGGTGGCGGTGC \\
\hline Aunc4 & & & At3gl3060 & GCCTGCCCGTGACGAGAGCGGTGCTACTATTAGGCATTTTACGAGTTAGCC \\
\hline Aunc5 & & & At3g19420 & $\begin{array}{l}\text { ATGCCTCCGTTTTCTCGTTTGGAGATGACGAGGACTCTGAAAGTGAGTAAAC } \\
\text { AAGG }\end{array}$ \\
\hline Aunc6 & & & At3g19760 & $\begin{array}{l}\text { CACAGAATTGGTCGTAGTGGACGTTTTGGAAGGAAGGGTGTTGCCATCAACT } \\
\text { TCG }\end{array}$ \\
\hline Aunc7 & & & At4g00660 & GCCGGTGATTGGTGGTGGAGAACCTTGATGTGACAGCAATGATGGGATGA \\
\hline
\end{tabular}

acetyl transferase (ShAC18, Genbank acc. X17220); GFP (Av AC19, Genbank acc. AF078810); Homo sapiens hemoglobin (HsAC20, Genbank acc. NM 000518); GUS (EcAC21, Genbank acc. A00196); E. coli hygromycin B phosphotransferase (EcAC22, Genbank acc. K01193); luciferase (PpAC23, Genbank acc. X65316); Neomycin phosphotransferase (EcAC24, Genbank acc. V00618).

Group 3, control oligos from human genes not expected to be expressed in plants: B-cell receptor protein (HsAC25, Genbank acc. AF126021); Mysoin heavy chain (HsAC26, Genbank acc. X13988); Myosin reg. light chain
2 (HsAC27, Genbank acc. M21812); Insulin-like growth factor (HsAC28, Genbank acc. X07868); cDNA FLJ10917fis (HsAC29, Genbank acc. AK001779); HSPC120 (HsAC30, Genbank acc. AF161469); $\beta 2$ microglobulin (HsAC31, Genbank acc. NM 004048); Phosphoglycerate kinase (HsAC32, Genbank acc. NM 000291); Tyrosine phosphatase (HsAC33, Genbank acc. L11329); G10 homolog edg-2 (HsAC34, Genbank acc. $\underline{\mathrm{U} 11861)}$.

Group 4, control oligos expected to have the same level of expression in all tissues based on analysis of Arabidopsis 
array data: Ubiquitin protein ligase (Aunc1, At1g14400, Genbank acc. T21817, ESTID103C16T7); unknown protein (Aunc2, At1g16210, Genbank acc. T04357, ESTID39A2T7); phosphatase (Aunc3, At1g43900, Genbank acc. H76500, ESTID196M23T7); unknown protein (Aunc4, At3g13060, Genbank acc. NM 112143, ESTID127j5t7); protein-tyrosine phosphatase (Aunc5, At3g19420, Genbank acc. NM 112829, ESTID122G23T7); translation initiation factor (Aunc6, At3g19760, Genbank acc. NM 112866.3, ESTID137B19T7); helicase (Aunc7, At4g00660, Genbank acc. NM 116291.4, ESTID221A7T7).

\section{Labelling of array samples}

Reverse transcription (RT) of mRNA in the total RNA samples was performed using an oligodT23V primer and with the incorporation of amino-allyl deoxyuridine (aadU, Sigma-Aldrich, Milwaulke, WI). Each RT reaction contained $50 \mu \mathrm{g}$ total RNA and 10 units Transcriptor Reverse Transcriptase (Roche, Indianapolis, IN) together with 10 $\mu \mathrm{M}$ oligodT23V, $1 \times$ first strand buffer (Roche, Indianapolis, IN), $6.6 \mu \mathrm{M}$ DTT, and nucleotides at $0.5 \mathrm{mM}$ for $\mathrm{dA}$, $\mathrm{dG}, \mathrm{dC}$ and $0.25 \mathrm{mM}$ for $\mathrm{dT}$ and aadU in a total volume of $30 \mu \mathrm{L}$. The RNA and oligodT23V were incubated at $70^{\circ} \mathrm{C}$ for $10 \mathrm{~min}$ and cooled to $4^{\circ} \mathrm{C}$ for $5 \mathrm{~min}$. First strand buffer, DTT, nucleotides and enzyme were added and the reaction was incubated for $30 \mathrm{~min}$ at $42^{\circ} \mathrm{C}$. $1 \mu \mathrm{L}$ of $20 \mathrm{mM}$ EDTA was added to stop the reaction, and RNA degraded by addition of $1 \mu \mathrm{L} 500 \mathrm{mM} \mathrm{NaOH}$ and the sample heated to $70^{\circ} \mathrm{C}$ for 10 min then neutralised with $1 \mu \mathrm{L} 500$ $\mathrm{mM} \mathrm{HCl}$.

Apple genomic DNA was isolated from Royal Gala leaves using a Nucleon extraction and purification kit (GE Healthcare). Leaves ( $1 \mathrm{~g}$ ) were processed according to the manufacturers instructions and the optional step of adding $\beta$-marcaptoethanol was included to limit oxidation of phenolic compounds. DNA was resuspended in $500 \mu \mathrm{L}$ TE. DNA was sheared by passing through a 26.5 gauge needle 20 times.

Genomic DNA first strand labelling used components of the Radprime DNA Labelling Kit (Invitrogen, Carlsbad, CA) containing Klenow DNA I polymerase and random octamer primers. Each labelling reaction contained $2.5 \mu \mathrm{g}$ sheared apple genomic DNA and 40 U Klenow together with $1 \times$ Radprime buffer (containing primers) and nucleotides at $0.12 \mathrm{mM} \mathrm{dA}, \mathrm{dG}, \mathrm{dC}$ and $0.06 \mathrm{mM} \mathrm{dT}$, aadU in a total volume of $50 \mu \mathrm{L}$. Radprime buffer and apple genomic DNA were heated to $95^{\circ} \mathrm{C}$ for $10 \mathrm{~min}$ and cooled to $4^{\circ} \mathrm{C}$ for $5 \mathrm{~min}$. The nucleotides and enzyme were added and the reaction was incubated for $1 \mathrm{hr}$ at $37^{\circ} \mathrm{C}$.

The cDNA and first strand gDNA was ethanol precipitated and resuspended in $5 \mu \mathrm{L} 100 \mathrm{mM} \mathrm{Na}_{2} \mathrm{CO}_{3}$ (pH 9.0). $5 \mu \mathrm{L}$
Cy3 or Cy5 (Amersham Biosciences, Buckinghamshire, England) in DMSO was added and the sample incubated at room temperature for $2 \mathrm{hr}$ in the dark. Unreacted dye was quenched by addition of $10 \mu \mathrm{L} 4 \mathrm{M}$ hydroxylamine (Sigma, St Louis, MO) and incubation for $10 \mathrm{~min}$ at room temperature in the dark. Labelled DNA was purified on PCR Clean-up Columns (Qiagen, Hilden, Germany) and paired samples were pooled. Sample absorbance at 260 $\mathrm{nm}, 550 \mathrm{~nm}$ and $650 \mathrm{~nm}$ was measured to determine the amount of labelled DNA and efficiency of Cy3 and Cy5 labelling, respectively. The PCR Clean-up Column purification was repeated once more after pooling to reduce background fluorescence.

\section{Hybridisation}

Labelled samples were hybridised to the microarray slides in an Amersham Lucidea Automated Slide Processor. Slides were pre-washed with $2 \times$ SSC, $0.3 \%$ SDS. Samples were injected into the slide chamber together in $3 \times \mathrm{SSC}$, $0.2 \%$ SDS, 6\% liquid blocking reagent (RPN3601, GE Healthcare, Chalfont St Giles, United Kingdom). Chambers were heated to $45^{\circ} \mathrm{C}$ and mixed overnight. After hybridisation, arrays were washed with $2 \times$ SSC, $0.3 \%$ SDS for $1.2 \mathrm{~min}$ and cooled to $30^{\circ} \mathrm{C}$, then washed again with $2 \times \mathrm{SSC}, 0.3 \%$ SDS for $1.2 \mathrm{~min}, 2 \times \mathrm{SSC}, 0.3 \%$ SDS for 2.4 minutes, $0.5 \times$ SSC, $0.2 \%$ SDS for $2.4 \mathrm{~min}$ (twice) and then once with $0.5 \times$ SSC. Slides were dried by centrifugation and scanned on a GenePix 4000 B Scanner (Axon Instruments). Raw data from scanning of the array slides were captured using GenePix4 (Axon Instruments) and automated spot alignment was augmented with manual checking of each slide to remove substandard spots.

\section{Normalisation and analysis}

All analysis was conducted as described in Schaffer et al. [22], except a one way ANOVA model ( $y=$ time) was used. The number of significant differentially expressed genes was examined using a 0.01 threshold using a non-adaptive False Discovery Rate (FDR) control [26]. Expression for each gene was calculated as the mean and standard error, of two technical replicates (dye swap) for both biological replicates for all timepoints (except for 0 DAA where no Rep2 sample was taken).

\section{Quantitative RT-PCR}

Primers for qRT-PCR were designed where possible to overlap the site of the oligo used on the array and qRTPCR carried out on cDNA made from RNA from the same tissue samples as used for the array experiments. The total RNA extracted for array experiment was used for the qRTPCR. RNA was treated with DNAase (using the Turbo DNAse kit, Ambion, Austin, TX).

Forward and reverse primers were designed for each qRTPCR candidate and three control genes. Where possible all 
Table 9: Primers used for qRT-PCR

\begin{tabular}{|c|c|c|}
\hline Genbank Acc. & Forward Primer & Reverse Primer \\
\hline EE663834 & 5'-CCATGCAAGTCTTGTTCCTG-3' & 3'-TCTTGGAGATGTGGTGAGGA-5' \\
\hline EBII552I & 5'-AGGCAGCCTTCTGTCATTG-3' & 3'-TCGAATTTCGCATTCTTCTG-5' \\
\hline EBI42488 & 5'-ACCGGAGCATGGAGACTTT-3' & 3'-GGACTAGCCAACATCACACTTG-5' \\
\hline$\overline{\mathrm{CN} 93 \mid 474}$ & 5'-AACTGAGTTGCTTGCAGTCC-3' & 3'-TGAGCCGGTTAGTAAAGCAA-5' \\
\hline$\overline{\mathrm{CN} 883166}$ & 5'-CCGTTGCGAAGGAAACTACT-3' & 3'-CTCCAACAGCAACACCAGAT-5' \\
\hline CN876582 & 5'-CGGAGGAAATTCAAGTCTACG-3' & 3'-GTTCCGGAATCCATCTTCAT-5' \\
\hline CN869994 & 5'-GTTGCTGATCACTCCACCAC-3' & 3'-CTTAGTCCTCAATCGGTCAACA-5' \\
\hline$\overline{\mathrm{CN} 878539}$ & 5'-GTGAGCACTGTTGAGCCATT-3' & 3'-AATGATTCCTTGAGCGGCTA-5' \\
\hline EBI38209 & 5'-GGAACCCTCAAACCATCATC-3' & 3'-GAGTATATCCACATGCCTTGGTC-5' \\
\hline CN899848 & 5'-ATCTTCGAGGGAGTGTACGG-3' & 3'-TCAACCGGCAAATCCTTAAT-5' \\
\hline$\overline{\mathrm{CN} 894184}$ & 5'-TCGAGTCAATTCAGGAAGGAG-3' & 3'-GCATATCATGGGCCAAATC-5' \\
\hline$\overline{E B \mid 40203}$ & 5'-CCCACAGTATAATGAGGAAGGA-3' & 5'-CCGGTGACTCACATGGAA-3' \\
\hline CN882408 & 5'-ССTCСTGATCTGTGGGAATTA-3' & 3'-TCAGAGACACTTGGGCTTGT-5' \\
\hline CN874609 & 5'-TTCAGCAACGAGGTGTCATT-3' & 3'-GAACTTGGTGGAGATGTTGC-5' \\
\hline$\overline{\mathrm{CN} 931994}$ & 5'-TGAGGAAGCCATTGTTCAAG-3' & 3'-CCTTTGAACATAGAGACCACCA-5' \\
\hline$\overline{\mathrm{CN} 876312}$ & 5'-AGTTACGGAGTGTGTTGAGCA-3' & 3'-CCAGGTAGTCACGGATGATG-5' \\
\hline EBI40237 & 5'-AGCTTGACTCTCCACCTCGT-3' & 3'-ATGGTGTTTCCATCAGCTTG-5' \\
\hline CN941270 & 5'-AAAGCAGAAGCCAGCAATC-3' & 3'-CCTTGTGGCTTCGAGTAACC-5' \\
\hline EBI34348 & 5'-CACTCAGCCAAATCAAGTCG-3' & 3'-ACACCCTATGGTCCTCGTTC-5' \\
\hline$\overline{\mathrm{EB} I 22025}$ & 5'-TGAGGTCGTATGGGAGAAAGA-3' & 3'-GCAGTGGTTAGACGGAAGCTA-5' \\
\hline CN929977 & 5'-TCAGAATCTCTTGCTAGCTCCTC-3' & 3'-CTTGCTCTGGCTACACGAAC-5' \\
\hline$\overline{E G 631180}$ & 5'-GCTGAAGGAGCTGTTGAGAA-3' & 3'-TCCCACCACTTGAACAAGAA-5' \\
\hline CN903005 & 5'-CGTTGGAGGTTGTGATGATG-3' & 3'-CCAACCAACCATCTAACTCTGA-5' \\
\hline CN946592 & 5'-AGCCTGAGATACACGGTGGT-3' & 3'-TGGTTCCCTCTCCTTTCAAT-5' \\
\hline CN940056 & 5'-ААСССТССТССТАССТТССТ-3' & 3'-AGCACCTATGCGACTGTGAC-5' \\
\hline$\overline{\mathrm{CN} 942749}$ & 5'-GTATCATGGTTGGCAATTCG-3' & 3'-CTGGAGTCCTTCACCTCGTAT-5' \\
\hline$\overline{E B} \mid 43812$ & 5'-CATTTGCCAGATGGTAGAGC-3' & 3'-GATTGCTCACACTCCCAAGA-5' \\
\hline$\overline{E G 631279}$ & 5'-CCGCCGTTTCTTCTATGTATT-3' & 3'-CAGAAGCTCCACATCCTTCTT-5' \\
\hline EBII6421 & 5'-ACCATGTGTCCCTCCTGTG-3' & 3'-TCGATCCGATTAAGAATGGAC-5' \\
\hline$\overline{\mathrm{EG} 631302}$ & 5'-TTACAGGTGTGCTGCATCAAT-3' & 3'-ATTCCAACCGTTGATCACATC-5' \\
\hline CN893819 & 5'-CGAAGGTGACACTССТСТCC-3' & 3'-CCGTTAGGTTGCTTGGTAGG-5' \\
\hline CN911241 & 5'-CGGAACGAATGATTGATGAG-3' & 3'-CATCTGGATTGAGTAGGAACTACC-5' \\
\hline$\overline{\mathrm{CN} 945543}$ & 5'-GAAAGTGAGTAATGGTGCTGCT-3' & 3'-GACTTGCTTCGGTTAAACACC-5' \\
\hline$\overline{\mathrm{CN} 903467}$ & 5'-ATGAGGACGATGAGGATGGT-3' & 3'-TCAAGCGTTGTCTCAACTCA-5' \\
\hline EBI24I37 & 5'-AAGCTCAAGCCCTCATGC-3' & 3'-GTGGATAAGCACCATTGCAG-5' \\
\hline EG631379 & 5'-ATACGAGGGCCCTATGGTT-3' & 3'-GAACCTGCAAACTTCAGCAA-5' \\
\hline$\overline{\mathrm{CN} 897963}$ & 5'-TACGCCCTCAAGTACAGCAA-3' & 3'-CAATTCCTCCGCCTCTTTAT-5' \\
\hline EE663644 & 5'-TGGGCTTCGGTACAAGTATG-3' & 3'-CACAATCTCCCAGGGATTTC-5' \\
\hline$\overline{\text { EE663791 }}$ & 5'-TTGTTCTGCAGCCATTCG-3' & 3'-ACGTGGAGAAGGATGAGGAT-5' \\
\hline EBI21923 & 5'-TGGTGGTAGGGTTGAAACTG-3' & 3'-CCCATACCTTCTCAAGGAACA-5' \\
\hline$\overline{\mathrm{EE} 663720}$ & 5'-GTTTCATTGGGAGGCTTGA-3' & 3'-GCCAGTCCCGAGGACTATAA-5' \\
\hline$\overline{E B I} \mid 2628$ & 5'-CCAAGTCGTCGTTGTTGCTA-3' & 3'-GGAGCGATGGAGATCTGTCT-5' \\
\hline EG631202 & 5'-GAGGCTGCCGTTTCTCTTAT-3' & 3'-CGTGCGATTTACCACTCATC-5' \\
\hline$\overline{E B I \mid 4557}$ & 5'-GTGCACGTTTCAACACCTTT-3' & 3'-GACTGCGGTAGAAGCAACAA-5' \\
\hline$\overline{\mathrm{CN} 884033}$ & 5'-CTTGCGAGAGTGTAGCGTTC-3' & 3'-AGTAGTCTGCACCCATCATCA-5' \\
\hline EBI44194 & 5'-CGCCTGCAAGGATTAGATTT-3' & 3'-TGTGCTCGGTTCCAGATATT-5' \\
\hline EE663790 & 5'-GGTCATGGATTGGAAGGGTA-3' & 3'-TGTGACAAACTGCTTACTGCTG-5' \\
\hline$\overline{E B I 56512}$ & 5'-CATCCTTCTGGAGTTGAGCA-3' & 3'-ATACACCATCCACCCAAACC-5' \\
\hline$\overline{E B I 23469}$ & 5'-AGGAACTCCGGAGACTCTTG-3' & 3'-AAGCCAACACAGGGATAACA-5' \\
\hline EBI08842 & 5'-AACTGGCTTGCGTGAGTATG-3' & 3'-TCACACCACTCATTGCTTCA-5' \\
\hline
\end{tabular}

primers were designed to span the array oligo, have an optimum temperature of $59^{\circ} \mathrm{C}$, GC content $40-60 \%$, amplicon length $100 \mathrm{bp}$, primer length 20 bp. Primer sequences are shown in Table 9.
Three independent reverse transcription reactions were performed for each RNA sample. All reactions contained $2 \mu \mathrm{g}$ of RNA, $2.5 \mu \mathrm{M}$ oligo(dT)23 V primer and $0.5 \mathrm{mM}$ dNTP mix in $36.5 \mu \mathrm{L} \mathrm{H}_{2} \mathrm{O}$. Sample were incubated $5 \mathrm{~min}$ at $65^{\circ} \mathrm{C}, 1 \mathrm{~min}$ on ice. $1 \times$ first strand buffer, $5 \mathrm{mM}$ DTT and 200 Units of Superscript III RT (Invitrogen, Carlsbad, 
CA) was added, samples incubated $60 \mathrm{~min}$ at $50^{\circ} \mathrm{C}$ and $15 \mathrm{~min}$ at $70^{\circ} \mathrm{C}$. Replicate reactions were pooled and diluted to $15 \mathrm{ng} / \mathrm{uL}$.

qRT-PCRs were carried out on both biological replicate samples and each reaction was carried out in quadruplicate. Each $20 \mu \mathrm{L}$ reaction contained $75 \mathrm{ng}$ cDNA, $200 \mathrm{nM}$ forward and reverse primer and $2 \times$ SYBR green master mix (Invitrogen, Carlsbad, CA) Amplification was performed using an ABI PRISM 7900 HT sequence detection system (Applied Biosystems, Foster City, CA). Reactions underwent a denaturation stage for $2 \mathrm{~min}$ at $94^{\circ} \mathrm{C}$, amplified for 40 cycles $\left(15 \mathrm{sec} 94^{\circ} \mathrm{C}, 30 \sec 59^{\circ} \mathrm{C}, 20 \mathrm{sec} 72^{\circ} \mathrm{C}\right.$ ) and a dissociation stage $\left(15 \mathrm{sec} 95^{\circ} \mathrm{C}, 30 \mathrm{sec} 60^{\circ} \mathrm{C}\right.$, $15 \mathrm{sec}$ $95^{\circ} \mathrm{C}$ ). Expression quantification and data analysis were performed in accordance with Snowden et al. [52].

\section{Authors' contributions}

BJJ designed the experiments, designed the oligos used in the array collected samples developed labelling and hybridisation methods, analysed the data and drafted the manuscript. KT carried out labelling and hybridisations, analysis of starch metabolic genes, qRT-PCR of starch genes and assisted with drafting the manuscript. RS assisted in developing hybridisation methods, processed raw array data and developed algorithms for normalisation. RA provided access to tomato array data and carried out analysis of apple data and assisted with the manuscript. LB carried out labelling and hybridisations. RB carried out labelling and hybridisations, qRT-PCR validation and assisted with the manuscript. JHB prepared RNA. RNC provided bioinformatic support and the scripts used to select unigenes and design the oligos used in the array. APG provided sequencing and bioinformatic support to confirm sequences for genes used in the array. SL prepared RNA and assisted with the manuscript. SMcA assisted in design of the experiments and managed the sample collection. FBP assisted in the design of algorithms for normalisation of the data. KCS assisted in design of the experiments and the oligos, analysed data and assisted with the manuscript. SW collected samples. All authors have read the final manuscript without any objections.

\section{Additional material}

\section{Additional file 1}

Array data. An Excel spreadsheet containing expression data for each array feature. Data is shown as mean, number of data points ( $n$ ) and standard error (SE) of expression levels for the two biological and two technical replicates for all samples except 0 DAA where only one biological replicate was sampled. In some cases one or more data points were excluded from analysis for technical reasons in which case the mean and standard error is calculated from the remaining data. Raw data is lodged with GEO.

Click here for file

[http://www.biomedcentral.com/content/supplementary/1471-

2229-8-16-S1.xls]

\section{Acknowledgements}

We'd like to acknowledge support from Jim Giovannoni and generous access to the tomato array data. BJ, KT, RS, LB, RB, JHB, RNC, APG, SL, $S M c A, F B P$, and SW were all supported by Funding from the Foundation for Research Science and technology (C06X0207), New Zealand and by Internal funding from HortResearch, NZ. RA was supported by NSF Plant Genome grant 05-01778.

\section{References}

I. Esau K: Anatomy of seed plants 2nd Edition. 2nd edition. Santa Barbara , John Wiley \& Sons, Inc; 1977.

2. Gillaspy G, Ben-David H, Gruissem W: Fruits: A Developmental Perspective. Plant Cell I993, 5(1 0): |439-I45I.

3. Giovannoni J: Molecular Biology of Fruit Maturation and Ripening. Annu Rev Plant Physiol Plant Mol Biol 200I, 52:725-749.

4. Giovannoni J]: Genetic regulation of fruit development and ripening. Plant Cell 2004, 16 Suppl:SI70-80.

5. Seymour GB, Taylor JE, Tucker GA: Biochemistry of fruit ripening. London, Chapman \& Hall; 1993:454.

6. Aharoni A, Keizer LC, Bouwmeester HJ, Sun Z, Alvarez-Huerta M, Verhoeven HA, Blaas J, van Houwelingen AM, De Vos RC, van der Voet H, Jansen RC, Guis M, Mol J, Davis RW, Schena M, van Tunen AJ, O'Connell AP: Identification of the SAAT gene involved in strawberry flavor biogenesis by use of DNA microarrays. Plant Cell 2000, I 2(5):647-662.

7. Trainotti L, Pavanello A, Casadoro G: Different ethylene receptors show an increased expression during the ripening of strawberries: does such an increment imply a role for ethylene in the ripening of these non-climacteric fruits? J Exp Bot 2005, 56(4 I 8):2037-2046.

8. Terrier N, Glissant D, Grimplet J, Barrieu F, Abbal P, Couture C, Ageorges A, Atanassova R, Leon C, Renaudin JP, Dedaldechamp F, Romieu C, Delrot S, Hamdi S: Isogene specific oligo arrays reveal multifaceted changes in gene expression during grape berry (Vitis vinifera L.) development. Planta 2005, 222(5):832-847.

9. Waters DL, Holton TA, Ablett EM, Lee LS, Henry RJ: cDNA microarray analysis of developing grape (Vitis vinifera cv. Shiraz) berry skin. Funct Integr Genomics 2005, 5(I):40-58.

10. Tanksley SD: The genetic, developmental, and molecular bases of fruit size and shape variation in tomato. Plant Cell 2004, 16 Suppl:SI8I-9.

II. Lemaire-Chamley M, Petit J, Garcia V, Just D, Baldet P, Germain V, Fagard M, Mouassite M, Cheniclet C, Rothan C: Changes in transcriptional profiles are associated with early fruit tissue specialization in tomato. Plant Physiol 2005, I39(2):750-769.

12. Fei Z, Tang X, Alba RM, White JA, Ronning CM, Martin GB, Tanksley SD, Giovannoni J]: Comprehensive EST analysis of tomato and comparative genomics of fruit ripening. Plant J 2004, 40(I):47-59. 
13. Alba R, Payton P, Fei Z, McQuinn R, Debbie P, Martin GB, Tanksley $S D$, Giovannoni J]: Transcriptome and selected metabolite analyses reveal multiple points of ethylene control during tomato fruit development. Plant Cell 2005, I 7( I I ):2954-2965.

14. Trainotti L, Bonghi C, Ziliotto F, Zanin D, Rasori A, Casadoro G, Ramina A, Tonutti P: The use of microarray [mu]PEACHI.0 to investigate transcriptome changes during transition from pre-climacteric to climacteric phase in peach fruit. Plant Science 2006, I 70(3):606-6I3.

15. Fonseca S, Hackler JL, Zvara A, Ferreira S, Balde A, Dudits D, Pais MS, Puskas LG: Monitoring gene expression along pear fruit development, ripening and senescence using cDNA microarrays. Plant Science 2004, I 67(3):457-469.

16. MacDaniels LH: The morphology of the apple and other pome fruits. Cornell Agricultural Experimental Station, Geneva, New York, USA Memoir 1940, 230: I-32

17. Denne MP: Fruit development and some tree factors affecting it. New Zealand Journal of Botany 1963, I:265-294.

18. Denne MP: The growth of apple fruitlets, and the effect of early thinning on fruit development. Annals of Botany 1960, 24(95):397-406.

19. Brookfield P, Murphy P, Harker R, MacRae E: Starch degradation and starch pattern indices; interpretation and relationship to maturity. Postharvest Biology and Technology 1997, I I:23-30.

20. Faragher JD, Brohier RL: Anthocyanin accumulation in apple skin during ripening: regulation by ethylene and phenylalanine ammonia-lyase. Scientia Horticulturae 1984, 22:89-96.

21. Reid MS, Rhodes MJC, Hulme AC: Changes in ethylene and CO2 during the ripening of apples. Journal of the Science of Food and Agriculture 1973, 24:971-979.

22. Schaffer RJ, Friel EN, Souleyre EJF, Bolitho K, Thodey K, Ledger S, Bowen JH, Ma JH, Nain B, Cohen D, Gleave AP, Crowhurst RN, Janssen BJ, Yao JL, Newcomb RD: A Genomics Approach Reveals That Aroma Production in Apple Is Controlled by Ethylene Predominantly at the Final Step in Each Biosynthetic Pathway. Plant Physiol 2007, I44(4): I899-1912

23. Marie D, Brown SC: A cytometric exercise in plant DNA histograms, with 2C values for 70 species. Biol Cell I993, 78(12):4I-5I.

24. Newcomb RD, Crowhurst RN, Gleave AP, Rikkerink EHA, Allan AC Beuning LL, Bowen JH, Gera E, Jamieson KR, Janssen BJ, Laing WA McArtney S, Nain B, Ross GS, Snowden KC, Souleyre EJF, Walton EF, Yauk YK: Analyses of Expressed Sequence Tags from Apple. Plant Physiol 2006, I4I(I): |47-I66.

25. Lee YP, Yu GH, Seo YS, Han SE, Choi YO, Kim D, Mok IG, Kim WT, Sung SK: Microarray analysis of apple gene expression engaged in early fruit development. Plant Cell Rep 2007.

26. Benjamini $Y$, Hochberg Y: Controlling the false discovery rate: a practical and powerful approach to multiple testing. Journal of the Royal Statistical Society 1995, 57:289-300.

27. Schoof H, Zaccaria P, Gundlach H, Lemcke K, Rudd S, Kolesov G, Arnold R, Mewes HW, Mayer KF: MIPS Arabidopsis thaliana Database (MAtDB): an integrated biological knowledge resource based on the first complete plant genome. Nucleic Acids Res 2002, 30(I):91-93.

28. Altschul SF, Gish W, Miller W, Myers EW, Lipman DJ: Basic loca alignment search tool. J Mol Biol 1990, 2 I 5(3):403-4I0.

29. Vandepoele K, Raes J, De Veylder L, Rouze P, Rombauts S, Inze D: Genome-wide analysis of core cell cycle genes in Arabidopsis. Plant Cell 2002, I4(4):903-916.

30. Menges $M$, de Jager SM, Gruissem W, Murray JA: Global analysis of the core cell cycle regulators of Arabidopsis identifies novel genes, reveals multiple and highly specific profiles of expression and provides a coherent model for plant cell cycle control. Plant J 2005, 4 I (4):546-566.

31. Smith AM, Zeeman SC, Smith SM: Starch degradation. Annu Rev Plant Biol 2005, 56:73-98.

32. Kanehisa $M$, Goto $S$, Hattori $M$, Aoki-Kinoshita KF, Itoh $M$, Kawashima S, Katayama T, Araki M, Hirakawa M: From genomics to chemical genomics: new developments in KEGG. Nucleic Acids Res 2006, 34(Database issue):D354-7.

33. Ferrandiz C, Pelaz S, Yanofsky MF: Control of carpel and fruit development in Arabidopsis. Annu Rev Biochem 1999 68:32I-354.
34. Volz RK, Harker FR, Lang S: Firmness Decline in 'Gala' Apple during Fruit Development. J Amer Soc Hort Sci 2003, I 28(6):797-802.

35. Lay-Yee M, Dellapenna D, Ross GS: Changes in mRNA and Protein during Ripening in Apple Fruit (Malus domestica Borkh. cv Golden Delicious). Plant Physiol 1990, 94(2):850-853.

36. Menges M, Murray JA: Synchronous Arabidopsis suspension cultures for analysis of cell-cycle gene activity. Plant J 2002, 30(2):203-212

37. Menges M, Hennig L, Gruissem W, Murray JA: Genome-wide gene expression in an Arabidopsis cell suspension. Plant Mol Biol 2003, 53(4):423-442.

38. Sorrell DA, Menges M, Healy JM, Deveaux Y, Amano C, Su Y, Nakagami H, Shinmyo A, Doonan JH, Sekine M, Murray JA: Cell cycle regulation of cyclin-dependent kinases in tobacco cultivar Bright Yellow-2 cells. Plant Physiol 200 I, I 26(3): I | | 4- I 223.

39. Boudolf V, Barroco R, Engler Jde A, Verkest A, Beeckman T, Naudts $M$, Inze D, De Veylder L: B I-type cyclin-dependent kinases are essential for the formation of stomatal complexes in Arabidopsis thaliana. Plant Cell 2004, I 6(4):945-955

40. Boudolf V, Vlieghe K, Beemster GT, Magyar Z, Torres Acosta JA, Maes S, Van Der Schueren E, Inze D, De Veylder L: The plant-specific cyclin-dependent kinase CDKB I; I and transcription factor E2Fa-DPa control the balance of mitotically dividing and endoreduplicating cells in Arabidopsis. Plant Cell 2004, I 6( I 0):2683-2692.

4I. Dewitte W, Murray JA: The plant cell cycle. Annu Rev Plant Biol 2003, 54:235-264.

42. Spruck C, Strohmaier H, Watson M, Smith AP, Ryan A, Krek TW, Reed SI: A CDK-independent function of mammalian Cks I: targeting of SCF(Skp2) to the CDK inhibitor p27Kipl. Mol Cell 200I, 7(3):639-650.

43. Menges M, Samland AK, Planchais S, Murray JAH: The D-Type Cyclin CYCD3; I Is Limiting for the G I-to-S-Phase Transition in Arabidopsis. Plant Cell 2006, I 8(4):893-906.

44. Sugimoto-Shirasu K, Roberts K: "Big it up": endoreduplication and cell-size control in plants. Curr Opin Plant Biol 2003. 6(6):544-553

45. Weinl C, Marquardt S, Kuijt SJ, Nowack MK, Jakoby MJ, Hulskamp M, Schnittger A: Novel functions of plant cyclin-dependent kinase inhibitors, ICKI/KRPI, can act non-cell-autonomously and inhibit entry into mitosis. Plant Cell 2005, I 7(6): I704-I722

46. Verkest A, Manes CL, Vercruysse S, Maes S, Van Der Schueren E, Beeckman T, Genschik P, Kuiper M, Inze D, De Veylder L: The cyclin-dependent kinase inhibitor KRP2 controls the onset of the endoreduplication cycle during Arabidopsis leaf development through inhibition of mitotic CDKA; I kinase complexes. Plant Cell 2005, I 7(6): I723-I736.

47. Gonzalez N, Hernould M, Delmas F, Gevaudant F, Duffe P, Causse M, Mouras A, Chevalier C: Molecular characterization of a WEEI gene homologue in tomato (Lycopersicon esculentum Mill.). Plant Mol Biol 2004, 56(6):849-86I.

48. Harada T, Kurahashi W, Yanai M, Wakasa Y, Satoh T: Involvement of cell proliferation and cell enlargement in increasing the fruit size of Malus species. Scientia Horticulturae 2005 , I 05(4):447-456.

49. Smith SM, Fulton DC, Chia T, Thorneycroft D, Chapple A, Dunstan $\mathrm{H}$, Hylton C, Zeeman SC, Smith AM: Diurnal changes in the transcriptome encoding enzymes of starch metabolism provide evidence for both transcriptional and posttranscriptional regulation of starch metabolism in Arabidopsis leaves. Plant Physiol 2004, I 36(I):2687-2699.

50. Yano M, Kato M, Ikoma Y, Kawasaki A, Fukazawa Y, Sugiura M, Matsumoto $\mathrm{H}$, Oohara $Y$, Nagao A, Ogawa K: Quantitation of carotenoids in raw and processed fruits in Japan. Food Science and Technology Research 2005, I I(I): I3-I8.

51. Chang S, Puryear J, Cairney J: A simple and efficient method for isolating RNA from pine trees. Plant Molecular Biology Reporter 1993, I I(2): I |3-1 |6.

52. Snowden KC, Simkin AJ, Janssen BJ, Templeton KR, Loucas HM, Simons JL, Karunairetnam S, Gleave AP, Clark DG, Klee HJ: The Decreased apical dominance I/Petunia hybrida CAROTENOID CLEAVAGE DIOXYGENASE8 gene affects branch production and plays a role in leaf senescence, root growth, and flower development. Plant Cell 2005, I 7(3):746-759.

53. Sol genomics network [http://www.sgn.cornell.edu/] 